FEDERAL RESERVE BANK OF SAN FRANCISCO

WORKING PAPER SERIES

\title{
A Simple Framework to Monitor Inflation
}

\author{
Adam Hale Shapiro \\ Federal Reserve Bank of San Francisco \\ June 2022 \\ Working Paper 2020-29 \\ https://www.frbsf.org/economic-research/publications/working-papers/2020/29/
}

\section{Suggested citation:}

Hale Shapiro, Adam. 2022. “A Simple Framework to Monitor Inflation," Federal Reserve Bank of San Francisco Working Paper 2020-29.

https://doi.org/10.24148/wp2020-29

The views in this paper are solely the responsibility of the authors and should not be interpreted as reflecting the views of the Federal Reserve Bank of San Francisco or the Board of Governors of the Federal Reserve System. 


\title{
A Simple Framework to Monitor Inflation
}

\author{
Adam Hale Shapiro*
}

June 14, 2022

\begin{abstract}
This paper proposes a simple framework to help monitor and understand movements in PCE inflation in real time. The approach is to decompose inflation using simple categorical-level regressions or systems of equations. The estimates are then used to group categories into components of PCE inflation. I review some applications of the methodology, and show how it can help explain inflation dynamics over recent episodes. The methodology shows that inflation remained low in the mid-2010s primarily because of factors unrelated to aggregate economic conditions. I also apply the methodology to the Covid-19 pandemic. The decomposition reveals that a majority of elevated inflation in core PCE inflation in the 2021-2022 period was due to "Covid-sensitive" categories, that is, those categories where prices and quantities moved the most at the onset of the pandemic. Finally, I show how the methodology can be applied in a dynamic fashion, labeling categories as either supply- or demand-driven by month. This decomposition allows one to assess the extent to which supply and demand factors are impacting inflation.
\end{abstract}

*Federal Reserve Bank of San Francisco, adam.shapiro@sf.frb.org. This paper stems from research done with Tim Mahedy. The views expressed are those of the author and do not necessarily reflect the views of the Federal Reserve Bank of San Francisco or the Federal Reserve System. 


\section{Introduction}

Interpreting inflation dynamics is one of the most hotly debated and researched topics in macroeconomics 11 Understanding inflation patterns is especially important to those tracking it in real time. Monetary and fiscal policy decisions, as well as the prices of financial assets, depend on the underlying factors that are pushing or pulling on inflation. This paper proposes a simple framework to help disentangle movements in PCE inflation in real time.

Like other decompositions of PCE inflation, such as the well-known core/noncore decomposition, the framework outlined here uses the underlying categorical measures of inflation provided by the Bureau of Economic Analysis (BEA). The novelty of the approach is to decompose inflation using simple categorical-level regressions. The methodology is general enough to encompass a wide range of decompositions and nests the core/non-core decomposition. Specifically, the researcher can specify any data-generating process for sectoral inflation - that is, the dynamics of the price index for a specific category of PCE. The categories are then labeled using the sectoral-specific estimates from the model, correspondingly split into different components and subcomponents of PCE inflation. I also show that the methodology can be expanded to include a more complex model or system of equations, for example, including an additional equation that governs sectoral quantities.

The key assumption of the methodology is that inflation dynamics are best explained at the categorical (or sectoral) level. There is ample evidence in the literature that this assumption holds. For example, the health care services sector is sensitive to prices administered by the government (that is, Medicare and Medicaid) as shown in Clemens and Gottlieb (2017), Clemens, Gottlieb, and Shapiro (2014), and Clemens, Gottlieb, and Shapiro (2016). Certain products, such as airline services Gerardi and Shapiro (2009) and technology goods Aizcorbe (2006) and Copeland and Shapiro (2016)), tend to strongly move with technological progress and sector-specific competitive pressures.

This study outlines some applications of the framework. The first application is a decomposition of core PCE inflation into cyclical and acyclical components, as done in Mahedy and Shapiro (2017) and Shapiro (2018), and similar to the analysis of Stock and Watson (2019). For each category, a standard Phillips curve is estimated. A category is then labeled

\footnotetext{
${ }^{1}$ See, for example, Fuhrer and Moore (1995) Goodfriend and King (2005), Primiceri (2006) and Stock and Watson (2007)
} 
as either cyclical or acyclical based on the size and sign of the t-statistic. If the sector's inflation rate shows a negative and statistically significant relationship with the unemployment gap, the sector is labeled as cyclical, otherwise it is labeled acyclical. Such a decomposition can help policy makers determine, in real time, whether inflation is moving for reasons due to aggregate demand or whether they are due to more industry-specific factors. For instance, during the mid-2010s when core PCE inflation remained persistently below the Federal Reserve's 2 percent target, despite tight labor market conditions. Many researchers and policymakers have noted that the Phillips curve relationship is no longer holding (for example, Leduc, Wilson, et al. (2017), Bullard (2018), Del Negro, Lenza, Primiceri, and Tambalotti (2020) and Hooper, Mishkin, and Sufi (2020)). However, at the time, Chair Janet Yellen cited industry-specific factors as responsible for holding back inflation pressures "..recent lower readings on inflation are partly the result of unusual reductions in certain categories."2 The cyclical/acyclical decomposition verifies Yellen's comments showing that, during this time period, cyclical inflation was on a steady rise from its lows during the financial crisis, while acyclical inflation remained subdued.

The next application I demonstrate is to track the effects of an economic crisis on inflation. In particular, I show how one can monitor the inflationary effects of the financial crisis and, more recently, the economic disruptions caused by Covid-19. This can be done by simply including a dummy variable into the Phillips curve model explaining inflation dynamics. In terms of the financial crisis, the decomposition shows that the initial decline in inflation was attributable to a steep decline in acyclical factors that were sensitive to the financial crisis. Subsequently, over the course of 2009, downward pressure came from cyclical factors sensitive to the onset of the financial crisis.

The methodology can be tailored to any particular event. The Covid-19 pandemic, for instance, brought about abrupt and severe supply and demand disruptions to economic activity. I use the methodology to measure the extent to which effects directly stemming from the pandemic were responsible for the decline and subsequent rise of inflation. The decomposition reveals that a majority of elevated inflation in core PCE inflation in the 20212022 period was due to "Covid-sensitive" categories, that is, those categories where prices and quantities moved the most at the onset of the pandemic. A further decomposition which

\footnotetext{
${ }^{2}$ Testimony before the Committee on Financial Services on July 13, 2017, U.S. House of Representatives, Washington, D.C., https://www.federalreserve.gov/newsevents/testimony/yellen20170712a.htm
} 
combines the groupings constructed in the Phillips curve analysis, reveals that a majority of the rise in inflation in the 2021-2022 period is attributable to acyclical Covid-sensitive categories. This decomposition reinforces the idea that the forces pushing on inflation in the post-pandemic period are atypical relative to past recessions, but also linked with the disruptions caused by Covid-19.

Finally, one can use the methodology to examine the separate roles of supply and demand factors in pushing or pulling on inflation. Specifically, a price and quantity equation can be estimated to identify whether certain categories are either demand or supply sensitive. To do so, I rely on the basic microeconomic theory of how prices and quantities respond to demand versus supply shifts. Shifts in demand should move both prices and quantities in the same direction, while shifts in supply should move them in opposite directions. The results show intuitive characteristics: demand pushes inflation down in recessions and supply shocks move headline inflation more than core inflation. The readings show that supply and demand factors are about equally responsible for elevated levels of core inflation in 2022, however, supply factors explain a majority of the rise in headline inflation in that period.

The study is organized as follows. In section 2 I provide a brief overview of the BEA data. I describe the methodology of decomposing PCE inflation in section 3. Here, I review the univariate case, the multivariate case, and vector autoregression models. In sections 4 and 5 I review some applications of the methodology. Section 4 discusses a decomposition based on the Phillips curve specification. Section 5 discusses how the methodology can be applied to tracking the inflationary effects of an economic crisis-specifically, the financial crisis and the Covid-19 pandemic. In Section 6 I show how the decomposition can be applied in a dynamic fashion, decomposing inflation into supply- and demand-drive contributions. I conclude in section 7 .

\section{Data}

The price and quantity data used in this study are publicly available and come from the Bureau of Economic Analysis (BEA). The data on the underlying detail of quantity, price, and expenditures of the PCE index are availble in Tables 2.4.3U, 2.4.4U and 2.4.5U in the "Underlying Detail" page of the BEA's website.

The BEA constructs different levels of aggregation depending on the category of product. 
I use the fourth level of disaggregation, for example, (1) services $\rightarrow$ (2) transportation services $\rightarrow$ (3) public transportation $\rightarrow$ (4) air transportation. Such an aggregation leaves 124 categories in the core PCE index. Data at this level disaggregation are generally available back to 1988, although some series at this level are available at earlier dates.

\section{Decomposing Core PCE Inflation}

Inflation is constructed as an aggregate of inflation rates by sector, such that

$$
\pi_{t}=\sum_{i} \omega_{i} \pi_{i, t}
$$

where $\omega_{i}$ is the expenditure weight of sector $i$ in the household consumption basket. Since inflation is a weighted sum of sectoral inflation rates, it can easily be divided by sector into subcomponents. The most simple and well-known example of a division of inflation is core PCE inflation. Here, overall inflation is divided into a core component and non-core component depending on whether the sector $i$ belongs to the food or energy sectors:

$$
\pi_{t}=\underbrace{\sum_{i}\left(1-\mathbb{1}_{i \in f, e}\right) \omega_{i} \pi_{i, t}}_{\text {core }}+\underbrace{\sum_{i} \mathbb{1}_{i \in f, e} \omega_{i} \pi_{i, t}}_{\text {non-core }}
$$

where $\mathbb{1}_{i \in f, e}$ is the indicator function:

$$
\mathbb{1}_{i \in f, e}= \begin{cases}1 & \text { if } i=\operatorname{energy}(e) \text { or } i=f o o d(f) \\ 0 & \text { otherwise }\end{cases}
$$

The core/non-core decomposition is defined subjectively on the premise that prices in the food and energy sectors tend to be more volatile. Thus, the core/non-core decomposition allows researchers to focus on the less volatile component of overall inflation. The novelty of the approach discussed below is to use a statistical threshold to group categories. Specifically, the methodology proposed in this study is to base the decomposition of inflation on some statistical property of inflation in the sector - namely, the sensitivity of the sector to some economic variable or event. 


\subsection{Univariate Case}

I begin with an example where inflation in each sector is a function of a single observable macroeconomic variable $x_{t}$ :

$$
\pi_{i, t}=\beta_{i} x_{t}+\varepsilon_{i, t}
$$

where $\varepsilon_{i, t}$ is iid shock to industry $i$ at time $t$. It follows that one can decompose $\pi_{i, t}$ based on the coefficient $\beta_{i}$. Specifically, $\pi_{i, t}$ can be labeled as either being sensitive to $x_{t}$ or insensitive to $x_{t}$ by assessing the size and precision of the regression coefficient $\beta_{i}$ from a regression of $\pi_{i, t}$ on $x_{t}$ by sector. The threshold for sensitivity based on the t-statistic of $\hat{\beta}_{i}$ is then:

$$
\mathbb{1}_{i \in \text { sens }}= \begin{cases}1 & \text { if }\left|\mathbf{t}\left(\beta_{i}\right)\right|>\mathbf{t}^{\mathbf{k}} \\ 0 & \text { otherwise }\end{cases}
$$

where the t-statistic threshold, $k$, is pre-defined and chosen by the user. It follows that overall inflation can be divided into two distinct components:

$$
\pi_{t}=\underbrace{\sum_{i}\left(1-\mathbb{1}_{i \in \text { sens }}\right) \omega_{i} \pi_{i, t}}_{\text {insensitive to } x}+\underbrace{\sum_{i} \mathbb{1}_{i \in \text { sens }} \omega_{i} \pi_{i, t}}_{\text {sensitive to } x}
$$

There are four things to note about this decomposition. First, the number of components is not limited to two, as one can define multiple thresholds of $k$, and therefore multiple subcomponents of inflation. Second, the independent variable $x_{t}$ can take on any observable information, including a time dummy or the lagged inflation of that sector. In the case of a time dummy, the decomposition would be by the degree of sensitivity to a specific event (for example, the outbreak of Covid-19). If the independent variable is lagged sectoral inflation, $\pi_{t-1}$, (that is, an AR1 process), the decomposition would be between persistent and nonpersistent inflation. Finally, the indicator function is not time varying. Thus, $\beta_{i}$, and hence the indicator function will depend on the sample period that (3) is estimated over.

\subsection{Multivariate Case}

The decomposition can easily be extended to the multivariate setting. Suppose that sectoral inflation is function of both $x_{t}$ and $y_{t}$, as well as a host of other variables represented by the 
$n \times 1$ vector $\mathbf{Z}$ :

$$
\pi_{i, t}=\beta_{i}^{x} x_{t}+\beta_{i}^{y} y_{t}+\mathbf{Z} \gamma+\varepsilon_{i, t},
$$

and the researcher is interested in decomposing inflation by sensitivity to both $x$ and $y$. It follows that a set of four indicator functions can be constructed:

$$
\begin{aligned}
& \mathbb{1}_{i, x, y}= \begin{cases}1 & \text { if }\left|\mathbf{t}\left(\beta_{i}^{x}\right)\right|>\mathbf{t}^{\mathbf{k}} \cap\left|\mathbf{t}\left(\beta_{i}^{y}\right)\right|>\mathbf{t}^{\mathbf{k}} \\
0 & \text { otherwise }\end{cases} \\
& \mathbb{1}_{i, x, 0}= \begin{cases}1 & \text { if }\left|\mathbf{t}\left(\beta_{i}^{x}\right)\right|>\mathbf{t}^{\mathbf{k}} \cap\left|\mathbf{t}\left(\beta_{i}^{y}\right)\right|<\mathbf{t}^{\mathbf{k}} \\
0 & \text { otherwise }\end{cases} \\
& \mathbb{1}_{i, 0, y}= \begin{cases}1 & \text { if }\left|\mathbf{t}\left(\beta_{i}^{x}\right)\right|<\mathbf{t}^{\mathbf{k}} \cap\left|\mathbf{t}\left(\beta_{i}^{y}\right)\right|>\mathbf{t}^{\mathbf{k}} \\
0 & \text { otherwise }\end{cases} \\
& \mathbb{1}_{i, 0,0}= \begin{cases}1 & \text { if }\left|\mathbf{t}\left(\beta_{i}^{x}\right)\right|<\mathbf{t}^{\mathbf{k}} \cap\left|\mathbf{t}\left(\beta_{i}^{y}\right)\right|<\mathbf{t}^{\mathbf{k}} \\
0 & \text { otherwise }\end{cases} \\
& \pi_{t}=\underbrace{\sum_{i} \mathbb{1}_{i, x, y} \omega_{i} \pi_{i, t}}_{\text {sensitive to } x \text { and } y}+\underbrace{\sum_{i} \mathbb{1}_{i, x, 0} \omega_{i} \pi_{i, t}}_{\text {sensitive to } x \text { only }} \\
&+\underbrace{\mathbb{1}_{i, 0, y} \omega_{i} \pi_{i, t}}_{\text {sensitive to } y \text { only }}+\underbrace{\sum_{i} \mathbb{1}_{i, 0,0} \omega_{i} \pi_{i, t}}_{\text {insensitive }}
\end{aligned}
$$

Here inflation is broken up into "quadrants" based on the $2 \times 2$ sensitivity outcomes. As in the univariate case, the threshold for sensitivity can be altered or expanded by changing the size and number of t-statistic cutoffs $\mathbf{t}^{\mathbf{k}}$. Note that a joint Wald-statistic can also be specified (i.e., F-test) if the user wants to account for the joint correlation of the coefficient estimates. 


\subsection{Vector Autoregressive Models}

Finally, the framework can be extended to vector auto-regressions (VARs). Suppose an additional piece of information $y_{i, t}$ relevant for inflation dynamics varies by sector, and is itself dependent on $x_{t}$ :

$$
\begin{aligned}
& \pi_{i, t}=\beta_{i}^{\pi, \pi} \pi_{i, t-1}+\beta_{i}^{\pi, y} y_{i, t-1}+\beta_{i}^{\pi, x} x_{t}+\varepsilon_{i, t}^{\pi} \\
& y_{i, t}=\beta_{i}^{y, \pi} \pi_{i, t-1}+\beta_{i}^{y, y} y_{i, t-1}+\beta_{i}^{y, x} x_{t}+\varepsilon_{i, t}^{y}
\end{aligned}
$$

and one can assume any covariance structure in the errors between sectors or between dependent variables for the same sector (i.e., $\operatorname{cov}\left(\varepsilon_{i, t}^{\pi}, \varepsilon_{i, t}^{y}\right) \neq 0$ ). The benefit of assessing the system of equations is that the additional information from $y_{i, t}$ can be used to decompose inflation. For example, one could include the sensitivity of $x$ on $y_{i}$ (that is, $\beta_{i}^{y, x}$ ) as additional information about sector $i$ 's sensitivity to $x$, in addition to $\beta_{i}^{\pi, x}$ :

$$
\mathbb{1}_{i \in \text { sens }}= \begin{cases}1 & \text { if }\left|\mathbf{t}\left(\beta_{i}^{\pi, x}\right)\right|>\mathbf{t}^{\mathbf{k}} \cap\left|\mathbf{t}\left(\beta_{i}^{y, x}\right)\right|>\mathbf{t}^{\mathbf{k}} \\ 0 & \text { otherwise }\end{cases}
$$

and it follows that inflation can be decomposed into two groups:

$$
\pi_{t}=\underbrace{\sum_{i}\left(1-\mathbb{1}_{i \in \text { sens }}\right) \omega_{i} \pi_{i, t}}_{\text {insensitive to } x}+\underbrace{\sum_{i} \mathbb{1}_{i \in \text { sens }} \omega_{i} \pi_{i, t}}_{\text {sensitive to } x}
$$

which is analogous to the decomposition in (4) but with a stricter definition about what constitutes sensitivity to $x$.

\section{Application: Phillips Curve Decomposition}

\subsection{Cyclical and Acyclical Inflation}

As a first application, I show how inflation can be decomposed by its sensitivity to the economic cycle, as performed in Mahedy and Shapiro (2017) and Shapiro (2018). This decomposition is useful because it ties in with the standard Phillips curve framework. This relationship posits that fluctuations in aggregate demand, and hence the economic cycle, 
directly impact inflation through firms' price setting behavior. An extensive literature examines the cyclical nature of inflation by estimating the slope of the Phillips curve (see, for example, Shapiro (2008) and Mavroeidis, Plagborg-Møller, and Stock (2014)). The key assumption of this decomposition is that price-setting behavior varies by sector and that certain sectors may be more sensitive to aggregate-demand conditions than others. There is evidence in the literature that this assumption holds. For example, the health care services sector is sensitive to prices administered by the government (that is, Medicare and Medicaid) as shown in Clemens and Gottlieb (2017), Clemens, Gottlieb, and Shapiro (2014), and Clemens, Gottlieb, and Shapiro (2016). Certain products, such as airline services Gerardi and Shapiro (2009) and technology goods (Copeland and Shapiro (2016), tend to strongly move with competitive pressure.

The Mahedy and Shapiro (2017) decomposition assumes that inflation dynamics can be described by a sectoral-level Phillips curve in gap form (for example, Faust and Wright (2013)):

$$
\pi_{i, t}=\beta_{i}^{u}\left(u_{t-1}^{*}-u_{t-1}\right)+\beta_{i}^{\pi} \pi_{t-1}+\left(1-\beta_{i}^{\pi}\right) \pi_{t}^{*}+\alpha_{i}+\varepsilon_{i, t}
$$

where $3^{3}$

$\pi_{i, t}$ is the monthly inflation rate of sector $i$

$u_{t}$ is the unemployment rate

$u_{t}^{*}$ is NAIRU

$\pi_{t}^{*}$ measures the expected trend level of inflation (the perceived inflation target)

$\alpha_{i}$ is a sectoral level constant (fixed effect)

and the decomposition between cyclical and acyclical inflation is based on the following indicator function:

$$
\mathbb{1}_{i \in \text { cyclical }}= \begin{cases}1 & \text { if } \mathbf{t}\left(\beta_{i}^{u}\right)>1.96 \\ 0 & \text { otherwise }\end{cases}
$$

where $t=1.96$ is the (two-sided) 95th percentile confidence value. Note that the absolute value around $\beta_{i}^{u}$ is not used since Mahedy and Shapiro (2017) chose to assume that a negative and significant relationship with the unemployment gap was deemed not sensitive to the cycle. Furthermore, the food and energy sectors are ignored such that the focus is

\footnotetext{
${ }^{3}$ The perceived inflation target is measured using the FRB/US model variable "PTR."
} 
decomposing core PCE inflation. The model is run on data from 1988 (the beginning of the granular BEA PCE price and quantity data) to the end of 2007, prior to the onset of financial crisis. Mahedy and Shapiro (2017) end the sample period before the financial crisis to ensure that the crisis did not impact the decomposition. Table 1 shows a list of the coefficients, $\beta_{i}^{u}$, in descending order, along with standard errors (SE) and the indicator function, marked "Cyclical."

The decomposition of cyclical and acyclical core PCE inflation takes the following form:

$$
\pi_{t, t-12}=\underbrace{\sum_{i}\left(1-\mathbb{1}_{i \in \text { cyclical }}\right) \omega_{i, t, t-12} \pi_{i, t, t-12}}_{\text {Acyclical Inflation }}+\underbrace{\sum_{i} \mathbb{1}_{i \in \text { cyclical }} \omega_{i, t} \pi_{i, t, t-12}}_{\text {Cyclical Inflation }}
$$

where $\pi_{t, t-12}$ is constructed as the 12-month change in core PCE inflation, $\pi_{i, t, t-12}$ is the 12-month change in sector $i$ 's inflation rate and the weights, $\omega_{i, t, t-12}$ are a geometric average of period $t-12$ through $t$ Fisher weights of the sector:

$$
\omega_{i, t, t-12}=\left[\prod_{k=1}^{12}\left[\left(\frac{p q_{i, t-k}}{\sum_{i} p q_{i, t-k}}+1\right) *\left(\frac{p q_{i, t-k-1}}{\sum_{i} p q_{i, t-k-1}}+1\right)\right]^{\frac{1}{2}}\right]^{\frac{1}{12}}-1
$$

where $p q_{i, t-k}$ is expenditure in sector $i$ in period $t-k$. Figure 1 shows the decomposition between cyclical and acyclical inflation over the course of the entire sample. These weights do not exactly match that of the BEA but are approximately equivalent. The data series is available at the Federal Reserve Bank of San Francisco's Indicators and Data Pag By construction the cyclical component of inflation follows the unemployment gap in the estimation sample period (that is, 1988-2007), while the acyclical component will not (see Figure 22). The plot shows that the cyclical component has a strong out-of-sample fit as well (that is, 2008-2022). Specifically, the in-sample correlation between the month-overmonth cyclical contribution and the unemployment gap is 51 percent while the out-of-sample correlation is 50 percent. The slope of the relationship has flattened, but the correlation has the statistical significance. By contrast, the acyclical contribution has correlations of 0.004 in sample, and 0.077 out of sample.

\footnotetext{
${ }^{4}$ https://www.frbsf.org/economic-research/indicators-data/cyclical-and-acyclical-core-pce-inflation/
} 


\subsection{Persistent and Non-persistent Inflation}

In a similar fashion, one can also decompose inflation into a persistent and non-persistent components based on the coefficient $\beta^{\pi}$, which governs the persistence of inflation in the Phillips curve:

$$
\mathbb{1}_{i \in \text { persistent }}= \begin{cases}1 & \text { if } \mathbf{t}\left(\beta_{i}^{\pi}\right)>2.32 \\ 0 & \text { otherwise }\end{cases}
$$

and it follows that inflation can be decomposed into a persistent and non-persistent component:

$$
\pi_{t, t-12}=\underbrace{\sum_{i}\left(1-\mathbb{1}_{i \in \text { persistent }}\right) \omega_{i, t, t-12} \pi_{i, t, t-12}}_{\text {Non-Persistent Inflation }}+\underbrace{\sum_{i} \mathbb{1}_{i \in \text { persistent }} \omega_{i, t} \pi_{i, t, t-12}}_{\text {Persistent Inflation }}
$$

which is shown in the first panel of Figure 8. The black area represents those sectors with positive monthly persistence in inflation and the gray area those sectors with zero or negative persistence. Such a decomposition could be useful in indicating whether a recent change in inflation will be more or less likely to persist going forward as is the motivation for the Federal Reserve Bank of Dallas's trimmed mean measure of PCE inflation (Dolmas (2005)). As discussed in Section 3.2, one can use both of the coefficients on the Phillips curve, $\beta_{i}^{u}$ and $\beta_{i}^{\pi}$, to decompose inflation even further:

$$
\begin{aligned}
\pi_{t} & =\underbrace{\sum_{i} \mathbb{1}_{i, \beta_{i}^{u}, \beta_{i}^{\pi}} \omega_{i} \pi_{i, t}}_{\text {Cyclical/Persistent }}+\underbrace{\sum_{i} \mathbb{1}_{i, \beta_{i}^{u}, 0} \omega_{i} \pi_{i, t}}_{\text {Cyclical/Non-persistent }} \\
& +\underbrace{\sum_{i} \mathbb{1}_{i, 0, \beta_{i}^{\pi} \omega_{i} \pi_{i, t}}}_{\text {Acyclical/Persistent }}+\underbrace{\sum_{i} \mathbb{1}_{i, 0,0} \omega_{i} \pi_{i, t}}_{\text {Acyclical/Non-Persistent }}
\end{aligned}
$$

where, for example, $\mathbb{1}_{i, \beta_{i}^{u}, \beta_{i}^{\pi}}$ indicates that both $\beta_{i}^{u}$ and $\beta_{i}^{\pi}$ are statistically significant and positive for sector $i$. This decomposition of core PCE inflation into four components is shown in the third panel of Figure 8. This decomposition, for instance, shows that the rise in inflation above 2 percent in the mid-2000s as well as the good portion of 2018 was driven to a large degree by not only acyclical factors, but non-persistent acyclical factors. 


\section{Application: Economic Crises}

As discussed above, we can assess the sectoral sensitivity of inflation to a specific date, namely the onset of an economic crisis. The assumption in this type of decomposition is that the factors that most directly linked to the crisis exogenously appear in the month when the crisis begins.

\subsection{Financial-Crisis Sensitive Inflation}

As a first example, we can assess the sensitivity of inflation to the financial crisis:

$$
\pi_{i, t}=\beta_{i}^{1} \mathbb{1}_{t \in 2008 m 9}+\alpha_{i}+\varepsilon_{i, t}^{\pi}
$$

where $\mathbb{1}_{t \in 2008 m 9}$ is a dummy variable indicating September 2008 - the month Lehman Brothers filed for bankruptcy and is commonly thought as the onset of the financial crisis. The coefficient $\beta_{i}^{1}$ will indicate those sectors whose prices moved the most in that month, and are presumably the most directly related to the crisis itself:

$$
\mathbb{1}_{i \in \text { sensitive }}= \begin{cases}1 & \text { if }\left|\mathbf{t}\left(\beta_{i}^{1}\right)\right|>2.32 \\ 0 & \text { otherwise }\end{cases}
$$

The first panel of Figure 4 shows the decomposition of inflation between crisis-sensitive (in gray) and crisis-insensitive (in black) inflation around the time of Lehman Brothers' collapse, marked by the red vertical line. By construction, there is a strong movement in crisis-sensitive inflation following the onset of the crisis. The decline in sensitive-inflation alleviates some after the initial shock rolls out of the 12-month change, it remains depressed well into 2010. By contrast crisis-insensitive inflation remains fairly steady throughout the crisis period. One can compare this to the behavior of cyclical inflation over the same period, shown in the first panel, which declines at much more gradual pace, inline with the gradual increase in unemployment that followed.

As an extension I can combine the two decompositions in a similar fashion as to that done in (11), by including the financial-crisis event dummy in the Phillips curve specification:

$$
\pi_{i, t}=\beta_{i}^{1} \mathbb{1}_{t \in 2008 m 9}+\beta_{i}^{u}\left(u_{t-1}^{*}-u_{t-1}\right)+\beta_{i}^{\pi} \pi_{t-1}+\left(1-\beta_{i}^{\pi}\right) \pi_{t}^{*}+\alpha_{i}+\varepsilon_{i, t}
$$


in which case one can do a similar multi-way decomposition of inflation using the estimated coefficients. This sample is run on the 1988m1-2008m9 sample, and I will use the estimates of $\beta_{i}^{1}$ and $\beta_{i}^{u}$, to decompose inflation into four separate categories:

$$
\begin{aligned}
& \pi_{t}=\underbrace{\sum_{i} \mathbb{1}_{i, \beta_{i}^{u}, \beta_{i}^{1}} \omega_{i} \pi_{i, t}}_{\text {Cyclical/Crisis-sensitive }}+\underbrace{\sum_{i} \mathbb{1}_{i, \beta_{i}^{u}, 0} \omega_{i} \pi_{i, t}}_{\text {Cyclical/Crisis-insensitive }} \\
&+\underbrace{\sum_{i} \mathbb{1}_{i, 0, \beta_{i}{ }^{1}} \omega_{i} \pi_{i, t}}_{\text {Acyclical/Crisis-sensitive }}+\underbrace{\sum_{i} \mathbb{1}_{i, 0,0} \omega_{i} \pi_{i, t}}_{\text {Acyclical/Crisis-insensitive }}
\end{aligned}
$$

where the four categories are decomposed as follows,

$$
\begin{aligned}
& \mathbb{1}_{i, \beta_{i}^{u}, \beta_{i}^{1}}= \begin{cases}1 & \text { if } \mathbf{t}\left(\beta_{i}^{u}\right)>\mathbf{t}^{\mathbf{k}} \cap\left|\mathbf{t}\left(\beta_{i}^{1}\right)\right|>\mathbf{t}^{\mathbf{k}} \\
0 & \text { otherwise }\end{cases} \\
& \mathbb{1}_{i, \beta_{i}^{u}, 0}= \begin{cases}1 & \text { if } \mathbf{t}\left(\beta_{i}^{u}\right)>\mathbf{t}^{\mathbf{k}} \cap\left|\mathbf{t}\left(\beta_{i}^{1}\right)\right|<\mathbf{t}^{\mathbf{k}} \\
0 & \text { otherwise }\end{cases} \\
& \mathbb{1}_{i, 0, \beta_{i}^{1}}= \begin{cases}1 & \text { if } \mathbf{t}\left(\beta_{i}^{x}\right)<\mathbf{t}^{\mathbf{k}} \cap\left|\mathbf{t}\left(\beta_{i}^{1}\right)\right|>\mathbf{t}^{\mathbf{k}} \\
0 & \text { otherwise }\end{cases} \\
& \mathbb{1}_{i, 0,0}= \begin{cases}1 & \text { if } \mathbf{t}\left(\beta_{i}^{x}\right)<\mathbf{t}^{\mathbf{k}} \cap\left|\mathbf{t}\left(\beta_{i}^{1}\right)\right|<\mathbf{t}^{\mathbf{k}} \\
0 & \text { otherwise }\end{cases}
\end{aligned}
$$

and the decomposition is shown in the far-right panel of Figure $45^{5}$

The four-way decomposition reveals a clear story as to how inflation evolved after the onset of the crisis. The initial decline in inflation was attributable to steep decline in acyclical factors, sensitive to the financial crisis. Over the course of 2009, cyclical factors, also sensitive to the financial crisis, gradually weighed on inflation as the unemployment rate gradually rose. The bounce back in inflation over the course of 2010 was attributable to crisis-related factors rolling off the 12-month change calculation.

\footnotetext{
${ }^{5}$ Note that in this case, $\beta_{i}^{u}$ is slightly different than that in Section 4.1 as it is estimated up to in the $1988 \mathrm{~m} 1-2008 \mathrm{~m} 9$ sample, as opposed to the $1988-2007 \mathrm{~m} 12$ sample in the previous section.
} 


\subsection{Covid-19 Sensitive Inflation}

The next application of a crisis decomposition is the Covid-19 pandemic, and I similarly include an event dummy in the Phillips curve set up:

$$
\pi_{i, t}=\beta_{i}^{1} \mathbb{1}_{t \in 2020 m 3}+\beta_{i}^{u}\left(u_{t-1}^{*}-u_{t-1}\right)+\beta_{i}^{\pi} \pi_{t-1}+\left(1-\beta_{i}^{\pi}\right) \pi_{t}^{*}+\alpha_{i}+\varepsilon_{i, t}
$$

where $\mathbb{1}_{t \in 2020 \mathrm{~m} 3}$ is a dummy variable indicating March 2020, the onset of the pandemic in the United states when various mandatory and voluntary social distancing, stay-at-home orders, or supply-chain disruptions came into place. Analogous to the setup for the financial crisis, the coefficient $\beta_{i}^{1}$ will capture the sectoral sensitivity to these measures, under the assumption that the effects of the crisis exogenously appear in the initial month.

The first panel of Figure 5 shows the decomposition between Covid-sensitive and Covidinsensitive inflation around the onset of the pandemic. In February 2019, Covid-sensitive and Covid-insensitive inflation contributed about the same to core PCE inflation: 1.0 and 0.9 percentage point, respectively. By June, the contributions from Covid-sensitive and Covid-insensitive inflation declined to 0.4 and 0.6 , respectively. Covid-sensitive inflation was therefore responsible for about two-thirds of the 0.9 percentage point decline in year-overyear inflation between February and June. Although Covid-insensitive inflation did decline between February and May, it was declining from a temporary high level in early 2020. Strikingly, the decomposition shows that almost the entire run-up in inflation in the post2021 period is due to Covid-sensitive inflation. That is, those same categories that pushed inflation down at the onset of the pandemic or the same categories that pushing inflation up in the 2021-2022 period.

The second panel re-displays the decomposition of cyclical and acyclical inflation (as shown in Figure 11, while the third panel shows a four-way decomposition analogous to that done in the decomposition with the financial crisis. This further decomposition reveals that both the decline and the rise in inflation was attributable to acyclical factors related to the

pandemic. Cyclical factors sensitive to the pandemic did not contribute as much to the fall and rise of core PCE inflation. 


\subsubsection{Demand and Supply Effects Due to Covid-19}

The Covid-19 pandemic brought about abrupt and severe supply and demand disruptions to economic activity. In particular, mandatory and voluntary social distancing likely reduced demand while supply disruptions also ensued. Specifically, many employees could no safely go in to their workplace reducing production in certain sectors below full capacity. To examine the separate roles of supply and demand factors, I further divide the categories within the Covid-sensitive inflation group. To do so, I rely on the basic microeconomic theory of how prices and quantities respond to demand versus supply shifts. Shifts in demand should move both prices and quantities in the same direction, while shifts in supply should move them in opposite directions.

As discussed in Section 7, the methodology can be expanded to include a system of equations. To keep this model as simple and tractable as possible, I ignore the Phillips curve specification and assume a seemingly unrelated univariate regression two-equation system of the form:

$$
\begin{aligned}
\pi_{i, t} & =\beta_{i}^{\pi, 1} \mathbb{1}_{t \in 2020 \mathrm{~m} 3}+\alpha_{i}^{\pi}+\varepsilon_{i, t}^{\pi} \\
\Delta x_{i, t} & =\beta_{i}^{x, 1} \mathbb{1}_{t \in 2020 \mathrm{~m} 3}+\alpha_{i}^{x}+\varepsilon_{i, t}^{x}
\end{aligned}
$$

and run this over the 2010m1-2020m6 sample. Here, the The decomposition between supply and demand sensitive categories takes the following form: 


$$
\begin{aligned}
& \mathbb{1}_{i \in \text { insens }}= \begin{cases}1 & \text { if }\left|\mathbf{t}\left(\beta_{i}^{\pi, 1}\right)\right|<\mathbf{t}^{\mathbf{k}} \cap\left|\mathbf{t}\left(\beta_{i}^{x, 1}\right)\right|<\mathbf{t}^{\mathbf{k}} \\
0 & \text { otherwise }\end{cases} \\
& \mathbb{1}_{i \in \text { sens }(d)}= \begin{cases}1 & \text { if }\left[\mathbf{t}\left(\beta_{i}^{\pi, 1}\right)<-\mathbf{t}^{\mathbf{k}} \cap \mathbf{t}\left(\beta_{i}^{x, 1}\right)<-\mathbf{t}^{\mathbf{k}}\right] \cup\left[\mathbf{t}\left(\beta_{i}^{\pi, 1}\right)>\mathbf{t}^{\mathbf{k}} \cap \mathbf{t}\left(\beta_{i}^{x, 1}\right)>\mathbf{t}^{\mathbf{k}}\right] \\
0 & \text { otherwise }\end{cases} \\
& \mathbb{1}_{i \in \text { sens }(s)}= \begin{cases}1 & \text { if }\left[\mathbf{t}\left(\beta_{i}^{\pi, 1}\right)<-\mathbf{t}^{\mathbf{k}} \cap \mathbf{t}\left(\beta_{i}^{x, 1}\right)>\mathbf{t}^{\mathbf{k}}\right] \cup\left[\mathbf{t}\left(\beta_{i}^{\pi, 1}\right)>\mathbf{t}^{\mathbf{k}} \cap \mathbf{t}\left(\beta_{i}^{x, 1}\right)<-\mathbf{t}^{\mathbf{k}}\right] \\
0 & \text { otherwise }\end{cases} \\
& \mathbb{1}_{i \in \text { sens }(a)}= \begin{cases}1 & \text { if } \mathbb{1}_{i \in \operatorname{sens}(d)}=0 \cap \mathbb{1}_{i \in \operatorname{sens}(s)}=0 \cap \mathbb{1}_{i \in \text { insens }}=0 \\
0 & \text { otherwise }\end{cases}
\end{aligned}
$$

where the $\operatorname{sen}(s)$ indicates the category is supply sensitive, sens $(d)$ the category is demand sensitive, and sens $(a)$ indicates the category is ambiguously sensitive to the Covid shockthat is, those Covid-sensitive categories with either a statistically significant change in price or quantity, but not a statistically significant change in both price and quantity ${ }^{6}$ Table 2 shows a list of the coefficients $\beta_{i}^{\pi, 1}$ and $\beta_{i}^{x, 1}$, in descending order of the former, along with the standard error and the indicator functions marked insensitive (insen), supply sensitive (Sup), demand sensitive (Dem), and ambiguously sensitive (Amb). Of course, in reality, products are affected by both shifts in demand and supply at any given time, but this simple differentiation allows us to see which type of shift is dominating.

The first panel of Figure 6 shows a scatterplot depicting the percent changes in price and quantity of these 124 categories, where circle sizes are proportional to core PEC expenditure shares. Sensitive categories are those that experienced a quantity or price change (either positive or negative) pre- and post-Covid 7 that is significantly different than its average price change over the preceding 10 years (that is, $\left|\beta_{i}^{\pi, 1}\right|>0$ or $\left|\beta_{i}^{x, 1}\right|>0$ ). Sensitive categories are generally those that lie furthest from the origin and are depicted in blue. Some categories

\footnotetext{
${ }^{6}$ To help reduce noise, I assess the 2-month change in the price and quantity indexes and move the event date to $2020 \mathrm{~m} 4$ - so the change in prices and quantities would be assessed over the Jan-Feb to Mar-Apr period.

${ }^{7}$ To help alleviate measurement error, I run specifications (17) and (18) using 2-month changes in prices and quantities as opposed to the usual 1-month change.
} 
are labeled as sensitive despite sitting fairly close to the origin. These are categories where prices and quantities are normally quite stable, and thus, the threshold for being sensitive to Covid is lower.

The second panel of Figure 6 shows where these Covid-sensitive categories lie in terms of price and quantity change. By construction, the demand-sensitive categories will lie in either the bottom-left (a negative demand shift) or top-right quadrant (a positive demand shift), while the supply-sensitive categories will lie in the top-left (a negative supply shift) or bottom-right quadrant (a positive supply shift). The figures shows that the demandsensitive categories, labeled in blue, primarily lie in the bottom-left quadrant, indicating they experienced a negative shift in demand. Analogously, the supply sensitive categories, labeled in red, lie in the top-left quadrant, indicating they experienced a negative supply shift. Those remaining sensitive categories placed in the "ambiguous", labeled in gray, lie to the left of the $\mathrm{y}$-axis and close to the x-axis, implying they had large quantity declines but only small price changes. This implies that these ambiguous categories may have experienced declines in both supply and demand.

In the third panel of Figure 6, I measure the extent to which these three sub-groups have contributed to the decline in core PCE inflation. The dark blue bars represent the contribution to core PCE from the categories in the demand-sensitive group, the red bars represent the contribution from the supply sensitive group, and the light blue bars the contribution from the ambiguous group. The contribution from the Covid-insensitive group are re-displayed in gray. The results show that demand-sensitive inflation began declining as early as March of 2020, subtracting 0.3pp from year-over-year core PCE inflation that month. By April, it was subtracting $0.7 \mathrm{pp}$ from year-over-year core PCE inflation. The effect from demand-sensitive factors slowly eroded since April, and then turned positive by early 2021.

\section{Dynamic Labeling}

As a final application, I show how the decomposition can be applied in a dynamic fashion. In the previous applications, each category is labeled once and its grouping remains fixed. For instance, "household paper products" was categorized as demand-sensitive and it is including in this grouping throughout the entire sample period. However, this ignores the possibility 
that this category may change groupings from one period to another. For instance, household paper products may be subsequently hit with a supply shock in a period beyond the onset of Covid-19.

To demonstrate dynamic labelling, I extend the supply and demand decomposition from Section 5.2.1. I allow a given category to switch labels from month-to-month, such that a category labeled as demand-driven one month is allowed to be labeled supply-driven the following month. I isolate the surprise change to the price level and the surprise change to the quantity level of each category. The surprise is defined as the residual from a onemonth ahead forecasting model - the contemporaneous surprises in price and quantity for a given category. Specifically, I run rolling 120-month window rolling regressions (i.e., $t \in$ $[T-119, T])$ :

$$
\begin{aligned}
p_{i, t} & =Z_{t-1} \gamma+\varepsilon_{i, t}^{p} \\
q_{i, t} & =Z_{t-1} \gamma+\varepsilon_{i, t}^{q}
\end{aligned}
$$

where,

$p_{i, t}$ is the $\log$ of the price index of category $\mathrm{i}$ in month $\mathrm{t}$

$q_{i, t}$ is the log of the quantity index of category i in month $\mathrm{t}$

$Z_{t-1}$ is vector of variables available in month $t-1$.

$\varepsilon_{i, t}^{p}$ is the surprise change to the price index of category i in month $\mathrm{t}$

$\varepsilon_{i, t}^{q}$ is the surprise change to the quantity index of category i in month $\mathrm{t}$

My preferred specification includes 12 lags of the log price level and the log quantity level of category $i$. Results appeared to be robust to changing this specification to 6 lags or up to 24 lags. Overall, this is analogous to a standard two-equation vector autoregression model (VAR). For each regression, I collect the final month (i.e., month $T$ ) residual. It follows that category $i$ in month $T$ is labeled as supply-driven if $\varepsilon_{i, T}^{p}$ and $\varepsilon_{i, T}^{q}$ are off opposite signs and demand-driven if $\varepsilon_{i, T}^{p}$ and $\varepsilon_{i, T}^{q}$ are off the same signs: 


$$
\begin{aligned}
& \mathbb{1}_{i \in \text { demand }}= \begin{cases}1 & \text { if } \varepsilon_{i, T}^{p}<0 \cap \varepsilon_{i, T}^{q}<0 \cup \varepsilon_{i, T}^{p}>0 \cap \varepsilon_{i, T}^{q}>0 \\
0 & \text { otherwise }\end{cases} \\
& \mathbb{1}_{i \in \text { supply }}= \begin{cases}1 & \text { if } \varepsilon_{i, T}^{p}<0 \cap \varepsilon_{i, T}^{q}>0 \cup \varepsilon_{i, T}^{p}>0 \cap \varepsilon_{i, T}^{q}<0 \\
0 & \text { otherwise }\end{cases}
\end{aligned}
$$

One issue that arises is the noise level of the residuals. Specifically, at what point is it too difficult to decipher whether the residual is non-zero. To account for this issue, one can simply relabel a category $i$ in month $T$ as "ambiguous" if either $\varepsilon_{i, t}^{p}$ or $\varepsilon_{i, t}^{q}$ are sufficiently close to zero. In this example, I define "sufficiently close to zero" as the middle $20 \%$ of the residuals in the respective regression sample distributions by category. In this example, I label those residuals as "ambiguous" if they have a t-statistic $<0.125$, under the null hypothesis that $\varepsilon_{i, t}^{j}$, for $j \in\{p, q\}$, among $\left\{\varepsilon_{i, T-12}^{p} \ldots, \varepsilon_{i,}^{p}\right\}$. I also exclude post-2020 residuals in the sample when running this test. This process is repeated for each roll of the regression. The user is, of course, free to choose different thresholds to re-label a category as ambiguous. The more conservative the threshold (i.e., the higher the t-statistic used to re-label categories as ambiguous) the larger the ambiguous category will be and the smaller the demand- and supply-driven contributions will be.

The demand- and supply-driven monthly contributions to inflation are constructed as the weighted sum of price changes for categories within a given label. The year-over-year contributions are constructed as the 12-month rolling sums of monthly contributions. An increase in demand due to anticipated supply changes (e.g., consumer hoarding) would be labeled demand-driven. This leaves the possibility of labeling categories as demand-driven even though the root cause of the demand change is an impending supply constraint.

There is not a considerable amount of switching between demand and supply shocks from month-to-month. Across all categories, approximately 80 percent of months had either the same type of shock in the previous period or an ambiguous shock in the previous period. As a robustness exercise to account for noise, I smoothed the residuals by taking the 3month trailing moving average of them for each category and the results did not change. Figure 7 provide more insight on category labeling. I depict the share of months where a 
given category was labeled as supply-driven and demand-driven in 2010-2019 (light blue) and 2021-2022 (dark blue). I show the ten categories with the largest increase in frequency between the pre- and post-pandemic periods. Categories with extraordinarily frequent supply changes during the inflation run-up in post-pandemic period (2021-2022) include those with known supply constraints such as new autos, energy, and repair services 8 . Categories with extraordinarily frequent demand shocks in 2021-2022 include mainly goods categories (e.g., clothing, toys, video equipment, and cookware).

Figure shows the year-over-year contributions to headline PCE inflation (Panel A) and core PCE inflation (Panel B) from supply- and demand-driven inflation between 2000 to the present. The patterns show some intuitive characteristics. The contribution of demanddriven inflation to both core and headline PCE inflation declines during recessions. The collapse in airline travel immediately after 9-11 is labeled as demand driven and the sharp energy declines of 2014 and 2015 are identified as supply driven.

\section{Conclusion}

This study provided an overview of a simple framework to monitor inflation patterns. The approach relies on running regressions or system of equations on categorical-level data. The approach is general enough to encompass a wide range of decompositions, nesting the core/non-core decomposition. Any data-generating process for inflation can be specified, as long as the categories can subsequently be labeled from the sectoral-specific estimates.

I demonstrate a few applications of the methodology and show how it can be useful to policymakers, researchers, and market participants. The cyclical/acyclical decomposition shows that weak inflation numbers during the mid-2010's were not attributable to a dormant Phillips curve, but were in fact attributable to dampened acyclical factors. The decomposition reveals that a majority of elevated inflation in core PCE inflation in the 2021-2022 period was due to "Covid-sensitive" categories, that is, those categories where prices and quantities moved the most at the onset of the pandemic. As new crises emerge, this methodology can be customized to help policymakers and researchers monitor its effects.

\footnotetext{
8 "Ovens, dishwashers and washing machines are break down like never before. But there's nobody to fix them." Washington Post, October 2020 "One Business That's Loving the Supply Chain Crisis" Slate, October 2021
} 


\section{References}

Aizcorbe, A. (2006): "Why did semiconductor price indexes fall so fast in the 1990s? A decomposition," Economic Inquiry, 44(3), 485-496.

Bullard, J. (2018): "The case of the disappearing Phillips Curve," in Presentation at the 2018 ECB Forum on Central Banking on the Macroeconomics of Price-and Wage-Setting, Sintra, Portugal. https://www. stlouisfed. org/ /media/files/pdfs/bullard/remarks/2018/bullard ecb sintra june, vol. 19, p. 2018.

Clemens, J., And J. Gottlieb (2017): "In the shadow of a giant: Medicare's influence on private physician payments," Journal of Political Economy, 125(1), 1-39.

Clemens, J., J. Gottlieb, and A. Shapiro (2014): "How Much Do Medicare Cuts Reduce Inflation?," FRBSF Economic Letter, 28.

Clemens, J., J. Gottlieb, and A. Shapiro (2016): "Medicare payment cuts continue to restrain inflation," FRBSF Economic Letter, 15.

Copeland, A., and A. Shapiro (2016): "Price setting and rapid technology adoption: The case of the PC industry," Review of Economics and Statistics, 98(3), 601-616.

Del Negro, M., M. Lenza, G. E. Primiceri, and A. Tambalotti (2020): "What's up with the Phillips Curve?," Discussion paper, National Bureau of Economic Research.

Dolmas, J. (2005): "Trimmed mean PCE inflation," Federal Reserve Bank of Dallas Working Paper, 506.

Faust, J., and J. H. Wright (2013): "Forecasting inflation," in Handbook of economic forecasting, vol. 2, pp. 2-56. Elsevier.

Fuhrer, J., AND G. Moore (1995): "Inflation persistence," The Quarterly Journal of Economics, 110(1), 127-159. 
Gerardi, K., and A. Shapiro (2009): "Does competition reduce price dispersion? New evidence from the airline industry," Journal of Political Economy, 117(1), 1-37.

Goodfriend, M., And R. G. King (2005): "The incredible Volcker disinflation," Journal of Monetary Economics, 52(5), 981-1015.

Hooper, P., F. S. Mishkin, and A. Sufi (2020): "Prospects for inflation in a high pressure economy: Is the Phillips curve dead or is it just hibernating?," Research in Economics, 74(1), 26-62.

Leduc, S., D. J. Wilson, ET AL. (2017): "Has the wage Phillips curve gone dormant?," FRBSF Economic Letter, 30, 16.

Mahedy, T., AND A. Shapiro (2017): "What's Down with Inflation?," FRBSF Economic Letter, 35.

Mavroeidis, S., M. Plagborg-Møller, and J. H. Stock (2014): "Empirical evidence on inflation expectations in the New Keynesian Phillips Curve," Journal of Economic Literature, 52(1), 124-88.

Primiceri, G. E. (2006): "Why inflation rose and fell: policy-makers' beliefs and US postwar stabilization policy," The Quarterly Journal of Economics, 121(3), 867-901.

Shapiro, A. (2008): "Estimating the new Keynesian Phillips curve: a vertical production chain approach," Journal of Money, Credit and Banking, 40(4), 627-666.

(2018): "Has Inflation Sustainably Reached Target?" FRBSF Economic Letter, 2018, 26.

Stock, J. H., and M. W. Watson (2007): "Why has US inflation become harder to forecast?," Journal of Money, Credit and banking, 39, 3-33.

_ (2019): "Slack and cyclically sensitive inflation," Discussion paper, National Bureau of Economic Research. 
Figure 1: Cyclical and Acyclical Core PCE Inflation

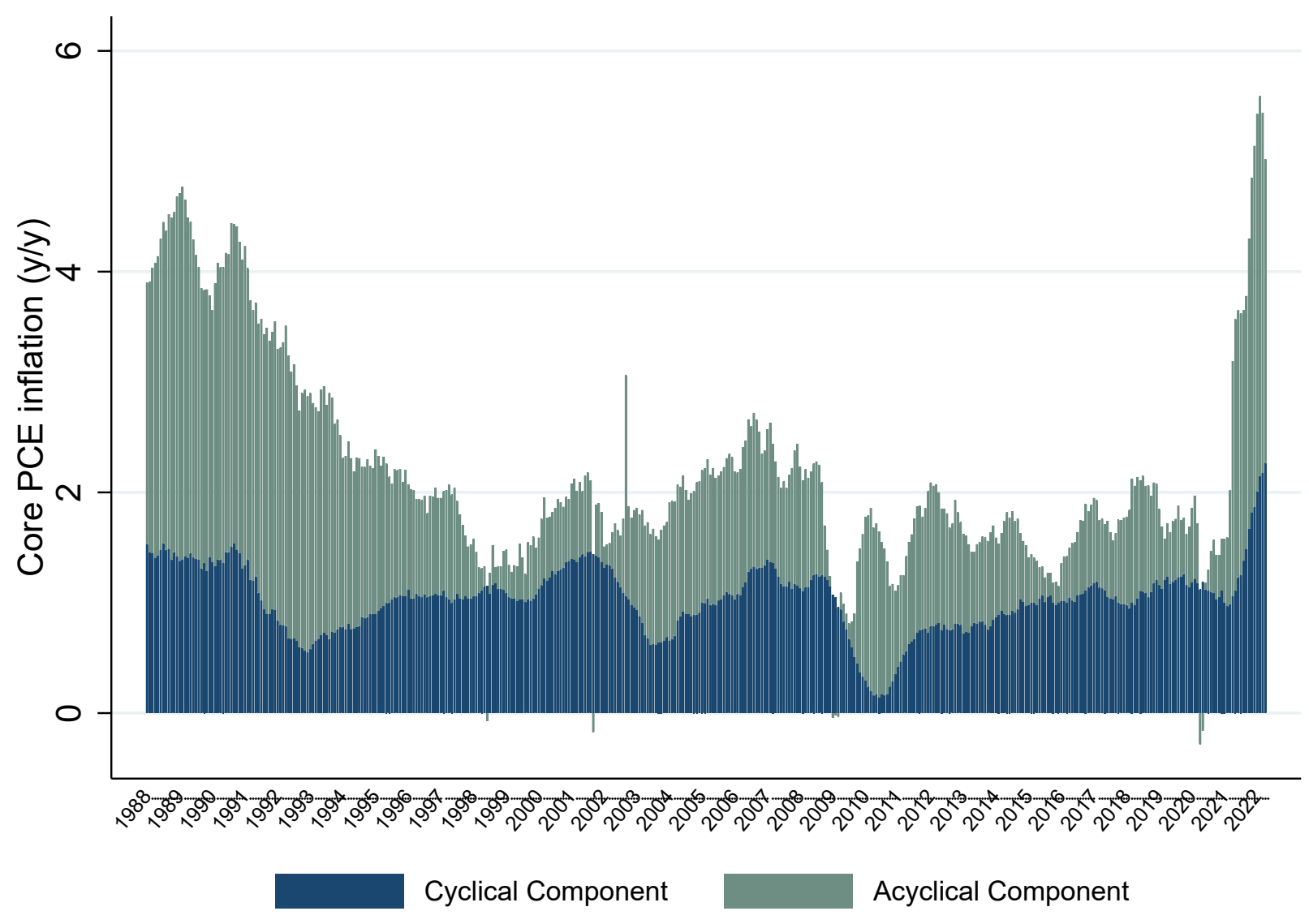

Notes: Contributions to year-over-year core PCE inflation from cyclical and acyclical categories. Cyclical categories are those with a statistically significant and positive coefficient on the slope of coefficient of the Phillips curve. Acyclical categories are all other core PCE categories. Series is available at FRBSF Cyclical and Acyclical Inflation 
Figure 2: Cyclical and Acyclical Inflation vs. Unemployment Gap
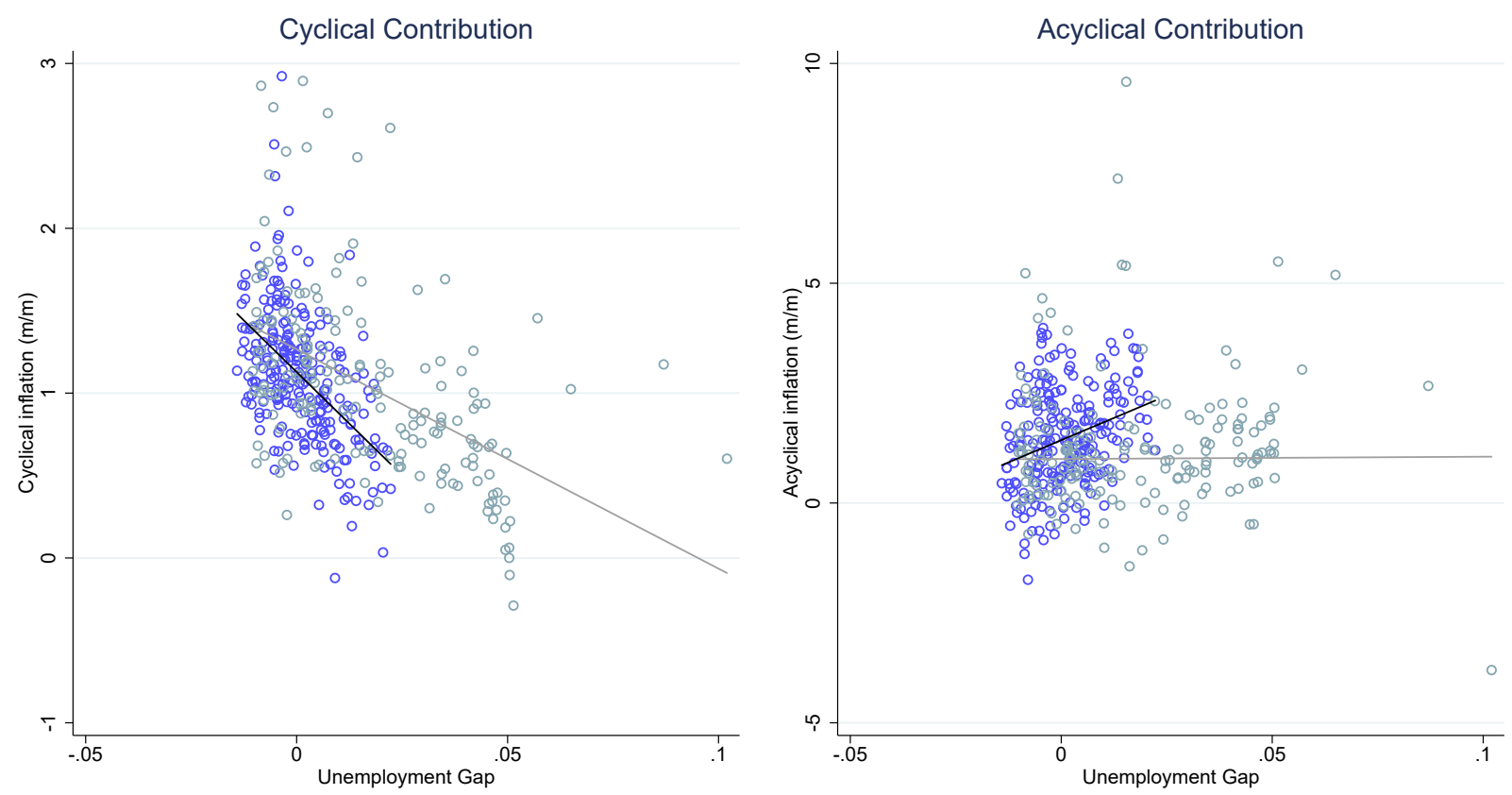

- In Sample $\circ$ Out of Sample

Notes: The left panel shows a scatter plot of the monthly (month-over-month) cyclical contributions (y-axis) against the unemployment gap $\left(u_{t}-u^{*}\right)$. The right figure shows the analogous scatter plot for the acyclical contributions. In dark blue are the in-sample periods: 1988-2007. In light blue are the out-of-sample periods: 2008-2022. 


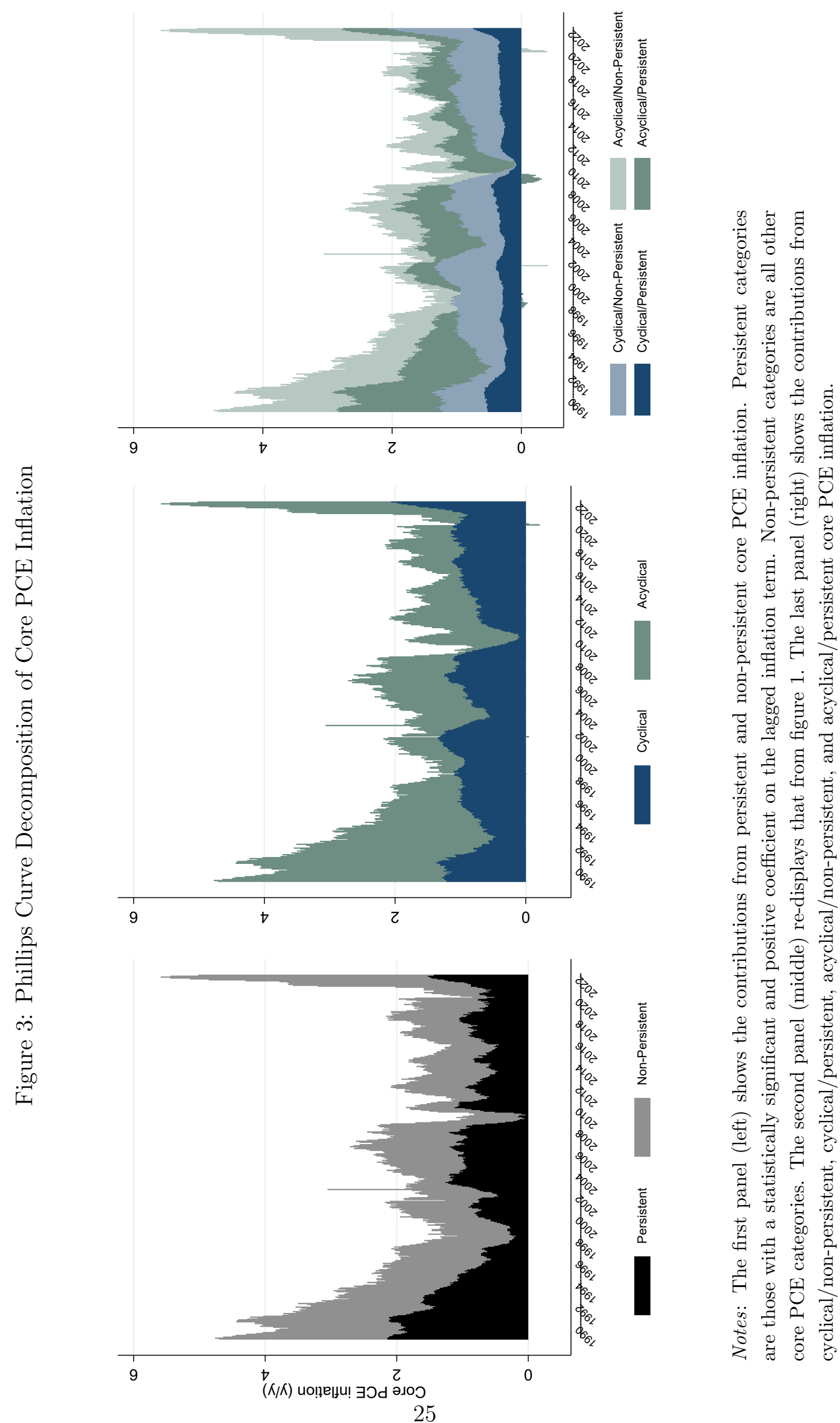




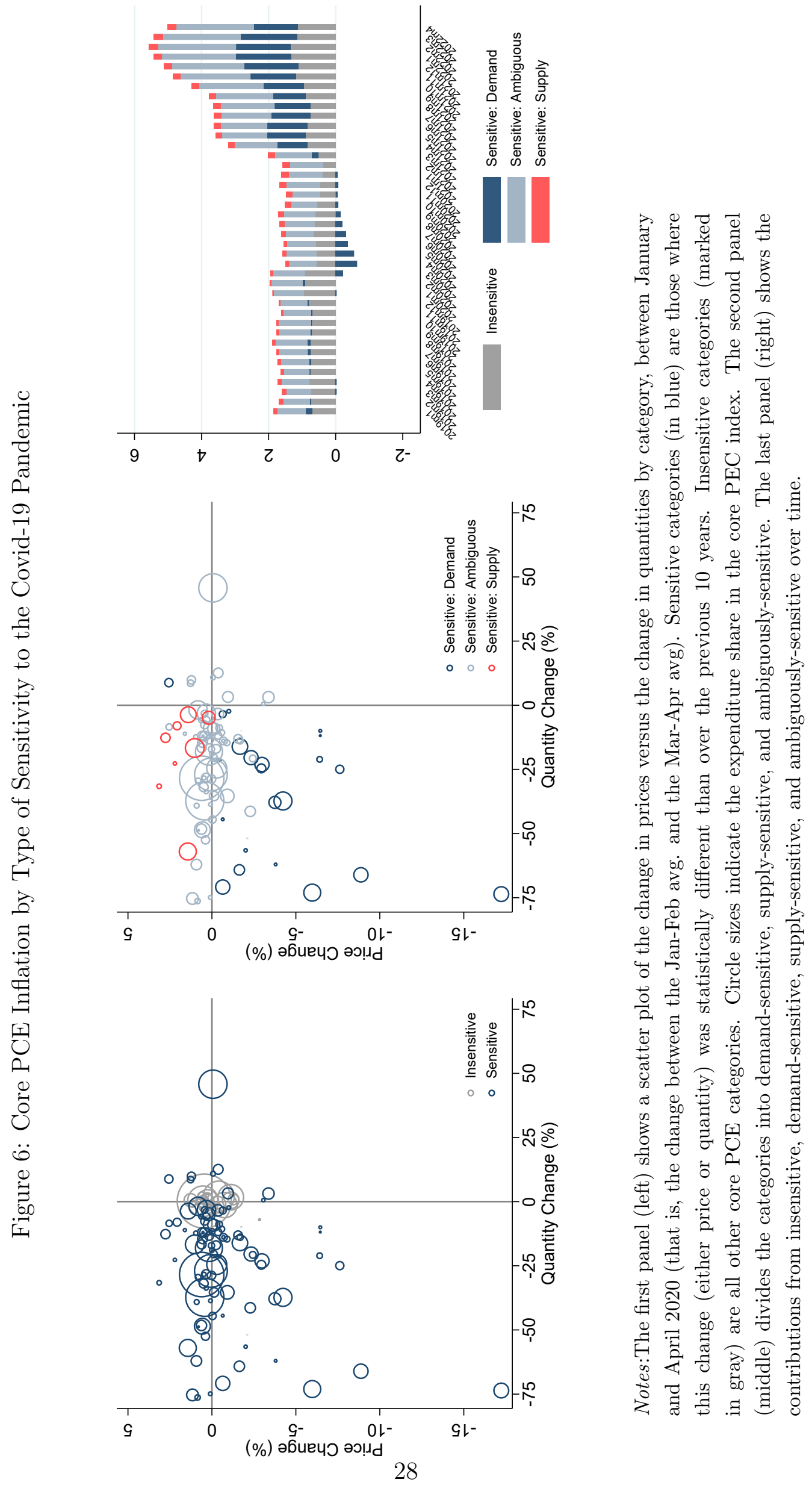


Table 1: Categories by Degree of Cyclicality

\begin{tabular}{|c|c|c|c|}
\hline Category & Cyclical & $\beta_{i}^{u}$ & $\mathrm{SE}$ \\
\hline Life Insurance & 0 & 2595 & 2769 \\
\hline Tobacco & 0 & 5.859 & 3.044 \\
\hline Nonprofit Institutions & 1 & 2.991 & 1.165 \\
\hline Household Paper Products & 1 & 2.546 & 0.492 \\
\hline Nursing Homes & 1 & 1.756 & 0.405 \\
\hline Household Cleaning Products & 1 & 1.673 & 0.313 \\
\hline Internet Access & 0 & 1.589 & 1.088 \\
\hline Admissions to Specified Spectator Amusements & 1 & 1.533 & 0.422 \\
\hline Museums \& Libraries & 1 & 1.310 & 0.452 \\
\hline Veterinary \& Other Services for Pets & 1 & 1.271 & 0.388 \\
\hline Tires & 0 & 1.266 & 0.579 \\
\hline Commercial \& Vocational Schools & 0 & 1.209 & 0.555 \\
\hline Labor Organization Dues & 1 & 1.205 & 0.348 \\
\hline Accessories \& Parts & 1 & 1.199 & 0.362 \\
\hline Religious Organizations' Services to HHs & 1 & 1.174 & 0.410 \\
\hline Educational Books & 0 & 1.161 & 0.518 \\
\hline Bicycles \& Acc & 1 & 1.126 & 0.443 \\
\hline Pleasure Boats, Aircraft \& Other Recral Vehicles & 1 & 1.125 & 0.445 \\
\hline Misc Household Products & 1 & 1.025 & 0.358 \\
\hline Child Care & 1 & 0.969 & 0.333 \\
\hline Package Tours & 1 & 0.874 & 0.256 \\
\hline Pets \& Related Products & 0 & 0.874 & 0.439 \\
\hline Amusement Parks/Campgrounds/Rel Recral Svcs & 1 & 0.873 & 0.255 \\
\hline Social Assistance & 1 & 0.873 & 0.234 \\
\hline Children's \& Infants' Clothing & 0 & 0.859 & 0.822 \\
\hline Less: Personal Remittances in Kind to Nonresidents & 1 & 0.850 & 0.308 \\
\hline Social Advocacy/Civic/Social Organizations & 1 & 0.747 & 0.226 \\
\hline Sales Receipts: Foundatns/Grant Making/Giving Svcs to HH & 0 & 0.736 & 0.354 \\
\hline Domestic Services & 1 & 0.734 & 0.295 \\
\hline Cosmetic/Perfumes/Bath/Nail Preparatns \& Implements & 0 & 0.734 & 0.439 \\
\hline Less: Exps in the US by Nonresidents & 0 & 0.694 & 0.366 \\
\hline Video Media Rental & 0 & 0.684 & 0.493 \\
\hline Carpets \& Other Floor Coverings & 0 & 0.677 & 0.634 \\
\hline Household Care Services & 1 & 0.656 & 0.192 \\
\hline Flowers, Seeds \& Potted Plants & 0 & 0.611 & 1.022 \\
\hline Cable, Satellite \& Oth Live Television Svc & 0 & 0.601 & 0.643 \\
\hline
\end{tabular}


Table 1: Categories by Degree of Cyclicality

\begin{tabular}{|c|c|c|c|}
\hline Category & Cyclical & $\beta_{i}^{u}$ & $\mathrm{SE}$ \\
\hline Motor Vehicle Maintenance \& Repair & 1 & 0.580 & 0.180 \\
\hline Purchased Meals \& Beverages & 1 & 0.575 & 0.106 \\
\hline Other Household Services & 0 & 0.573 & 0.395 \\
\hline Clothing \& Footwear Services & 1 & 0.565 & 0.199 \\
\hline Pari-Mutuel Net Receipts & 1 & 0.558 & 0.153 \\
\hline Casino Gambling & 1 & 0.558 & 0.153 \\
\hline Lotteries & 1 & 0.557 & 0.153 \\
\hline Major Household Appliances & 0 & 0.506 & 0.405 \\
\hline Window Coverings & 0 & 0.503 & 0.832 \\
\hline Elec Appliances for Personal Care & 0 & 0.503 & 0.450 \\
\hline Hair/Dental/Shave/Misc Pers Care Prods ex Elec Prod & 0 & 0.503 & 0.450 \\
\hline Imputed Rent of Owner-Occupied Nonfarm Hous & 1 & 0.487 & 0.128 \\
\hline Moving, Storage \& Freight Services & 0 & 0.476 & 0.334 \\
\hline Repair of Furn, Furnishings/Floor Coverings & 0 & 0.475 & 0.556 \\
\hline Repair of HH Appliances & 0 & 0.475 & 0.556 \\
\hline Musical Instruments & 0 & 0.457 & 0.400 \\
\hline Group Housing & 1 & 0.443 & 0.135 \\
\hline Rental of Tenant-Occupied Nonfarm Housing & 1 & 0.429 & 0.133 \\
\hline Net Health Insurance & 0 & 0.413 & 0.451 \\
\hline Prof Assn Dues & 0 & 0.379 & 0.321 \\
\hline Legal Services & 0 & 0.378 & 0.321 \\
\hline Food Furn to Empls Price Idx(inc Military) & 0 & 0.367 & 0.248 \\
\hline Corrective Eyeglasses \& Contact Lenses & 0 & 0.339 & 0.273 \\
\hline Nursery, Elementary \& Secondary Schools & 0 & 0.338 & 0.182 \\
\hline Maint/Repair of Rec Vehicles/Sports Eqpt & 0 & 0.332 & 0.350 \\
\hline Pharmaceutical Products & 0 & 0.327 & 0.243 \\
\hline Standard Clothing Issued to Military Personnel & 0 & 0.326 & 0.192 \\
\hline Hotels and Motels & 0 & 0.319 & 0.534 \\
\hline Women's \& Girls' Clothing & 0 & 0.275 & 0.391 \\
\hline Nonelectric Cookware \& Tableware & 0 & 0.269 & 0.510 \\
\hline Men's \& Boys' Clothing & 0 & 0.225 & 0.354 \\
\hline Jewelry & 0 & 0.210 & 0.994 \\
\hline Stationery \& Misc Printed Mtls & 0 & 0.163 & 0.537 \\
\hline Shoes \& Other Footwear & 0 & 0.127 & 0.398 \\
\hline Housing at Schools & 0 & 0.123 & 0.295 \\
\hline Film \& Photographic Supplies & 0 & 0.117 & 0.465 \\
\hline
\end{tabular}


Table 1: Categories by Degree of Cyclicality

\begin{tabular}{|c|c|c|c|}
\hline Category & Cyclical & $\beta_{i}^{u}$ & $\mathrm{SE}$ \\
\hline Dental Services & 0 & 0.116 & 0.197 \\
\hline Membership Clubs/Participant Sports Centers & 0 & 0.0571 & 0.435 \\
\hline Photo Studios & 0 & 0.0461 & 0.303 \\
\hline Net Household Insurance & 0 & 0.0327 & 0.882 \\
\hline Paramedical Services & 0 & 0.0150 & 0.254 \\
\hline Small Elec Household Appliances & 0 & 0.00355 & 0.526 \\
\hline Used Light Trucks & 0 & -0.0425 & 1.198 \\
\hline Accting \& Other Business Services & 0 & -0.0690 & 0.342 \\
\hline Outdoor Equip \& Supplies & 0 & -0.0787 & 0.553 \\
\hline Ground Transportation & 0 & -0.0843 & 0.458 \\
\hline Tools, Hardware \& Supplies & 0 & -0.0863 & 0.570 \\
\hline Sewing Items & 0 & -0.107 & 0.613 \\
\hline Clothing Materials & 0 & -0.107 & 0.613 \\
\hline Sporting Equip, Supplies, Guns \& Ammunition & 0 & -0.131 & 0.561 \\
\hline Foreign Travel by U.S. Residents & 0 & -0.146 & 0.433 \\
\hline Funeral \& Burial Services & 0 & -0.154 & 0.196 \\
\hline Postal \& Delivery Services & 0 & -0.175 & 1.650 \\
\hline Therapeutic Medical Equip & 0 & -0.204 & 0.291 \\
\hline Other Medical Products & 0 & -0.204 & 0.291 \\
\hline Hospitals & 0 & -0.224 & 0.315 \\
\hline Rental Value of Farm Dwellings & 0 & -0.235 & 0.157 \\
\hline Recreational Books & 0 & -0.257 & 0.423 \\
\hline Other Motor Vehicle Services & 0 & -0.288 & 0.521 \\
\hline Info Processing Equip & 0 & -0.303 & 0.935 \\
\hline Photo Processing & 0 & -0.310 & 0.225 \\
\hline Physician Services & 0 & -0.317 & 0.295 \\
\hline Financial Services Furnished w/out Payment & 0 & -0.451 & 0.664 \\
\hline Watches & 0 & -0.464 & 0.832 \\
\hline New Autos & 0 & -0.473 & 0.157 \\
\hline Household Linens & 0 & -0.479 & 0.726 \\
\hline Dishes and Flatware & 0 & -0.480 & 0.702 \\
\hline Newspapers \& Periodicals & 0 & -0.483 & 0.303 \\
\hline Video \& Audio Equip & 0 & -0.489 & 0.541 \\
\hline Water Supply \& Sewage Maintenance & 0 & -0.517 & 0.219 \\
\hline Garbage \& Trash Collection & 0 & -0.541 & 0.302 \\
\hline New Light Trucks & 0 & -0.550 & 0.198 \\
\hline
\end{tabular}


Table 1: Categories by Degree of Cyclicality

\begin{tabular}{lccc} 
Category & Cyclical & $\beta_{i}^{u}$ & $\mathrm{SE}$ \\
\hline Telecommunication Services & 0 & -0.572 & 0.463 \\
Clock/Lamp/Lighting Fixture/Othr HH Decorative Item & 0 & -0.593 & 0.716 \\
Photographic Equip & 0 & -0.729 & 0.540 \\
Luggage \& Similar Personal Items & 0 & -0.759 & 1.757 \\
Furniture & 0 & -0.785 & 0.363 \\
Motorcycles & 0 & -0.913 & 0.487 \\
Repr of Audio-Visual/Photo/Info Process Eqpt & 0 & -0.915 & 0.452 \\
Games, Toys \& Hobbies & 0 & -1.013 & 0.589 \\
Water Transportation & 0 & -1.057 & 0.953 \\
Used Autos & 0 & -1.240 & 0.775 \\
Higher Education & 0 & -1.268 & 0.365 \\
Telephone and Related Communication Equipment & 0 & -1.590 & 0.729 \\
Expenditures Abroad by U.S. Residents & 0 & -1.724 & 1.344 \\
Financial Service Charges, Fees/Commissions & 0 & -1.987 & 1.111 \\
Air Transportation & 0 & -5.038 & 5.468 \\
Net Motor Vehicle/Oth Transportation Insur & 0 & -11.93 & 9.438 \\
\hline
\end{tabular}


Figure 7: Share of months with surprise change in supply and demand

Panel A: Share of months with a surprise change in supply (ordered by difference between pre- and post-period)

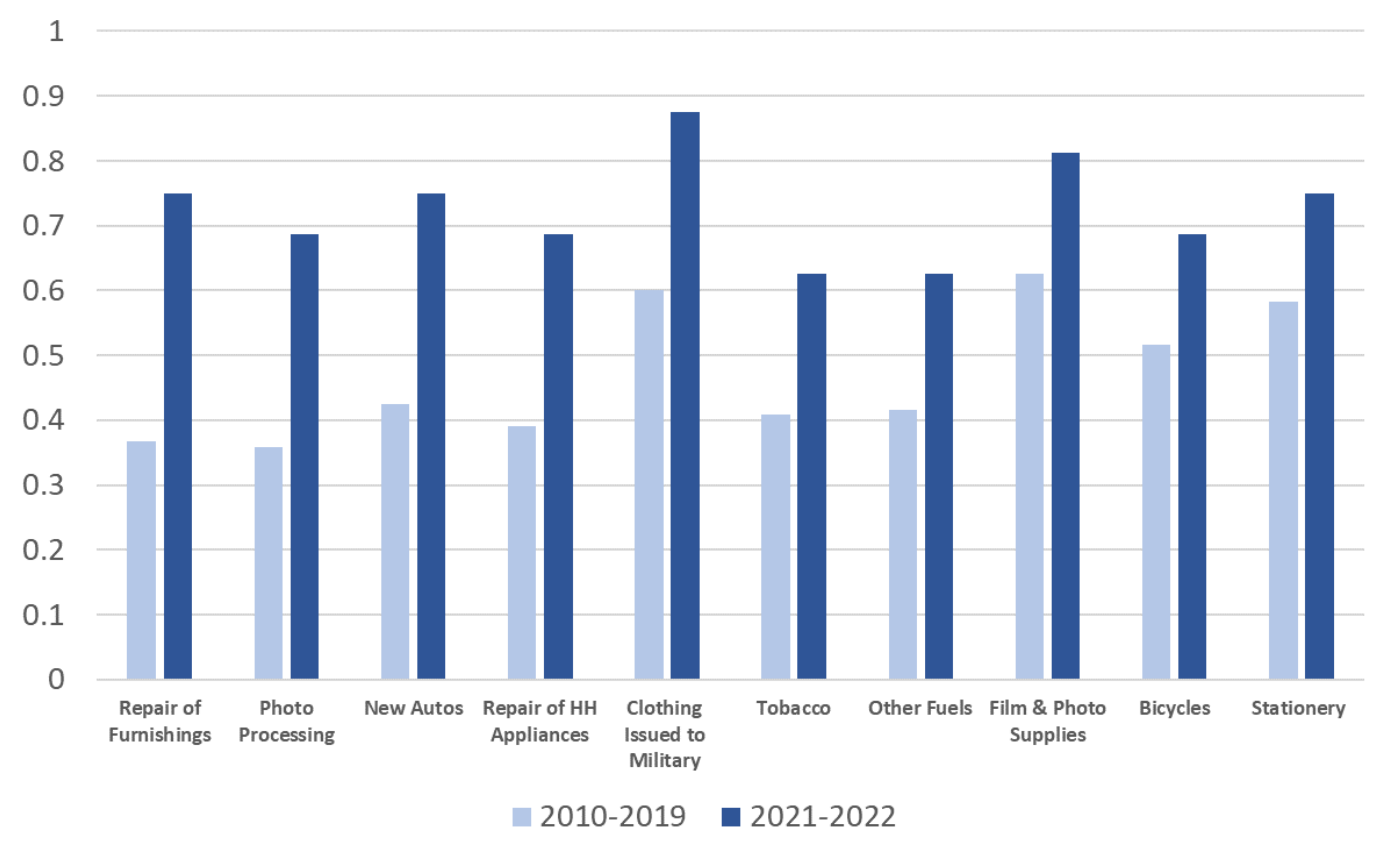

Panel B: Share of months with a surprise change in demand (ordered by difference between pre- and post-period)

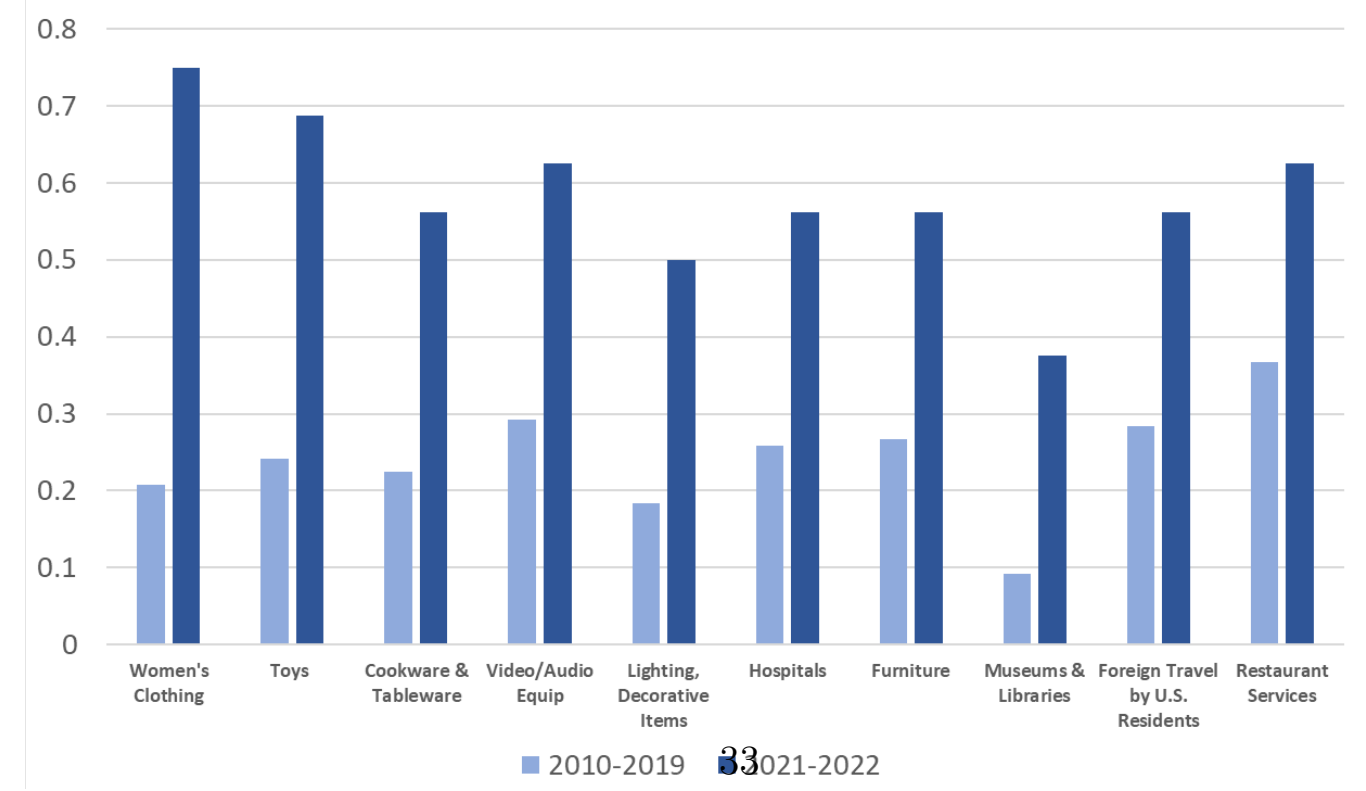


Figure 8: Supply- and Demand-Driven PCE Inflation

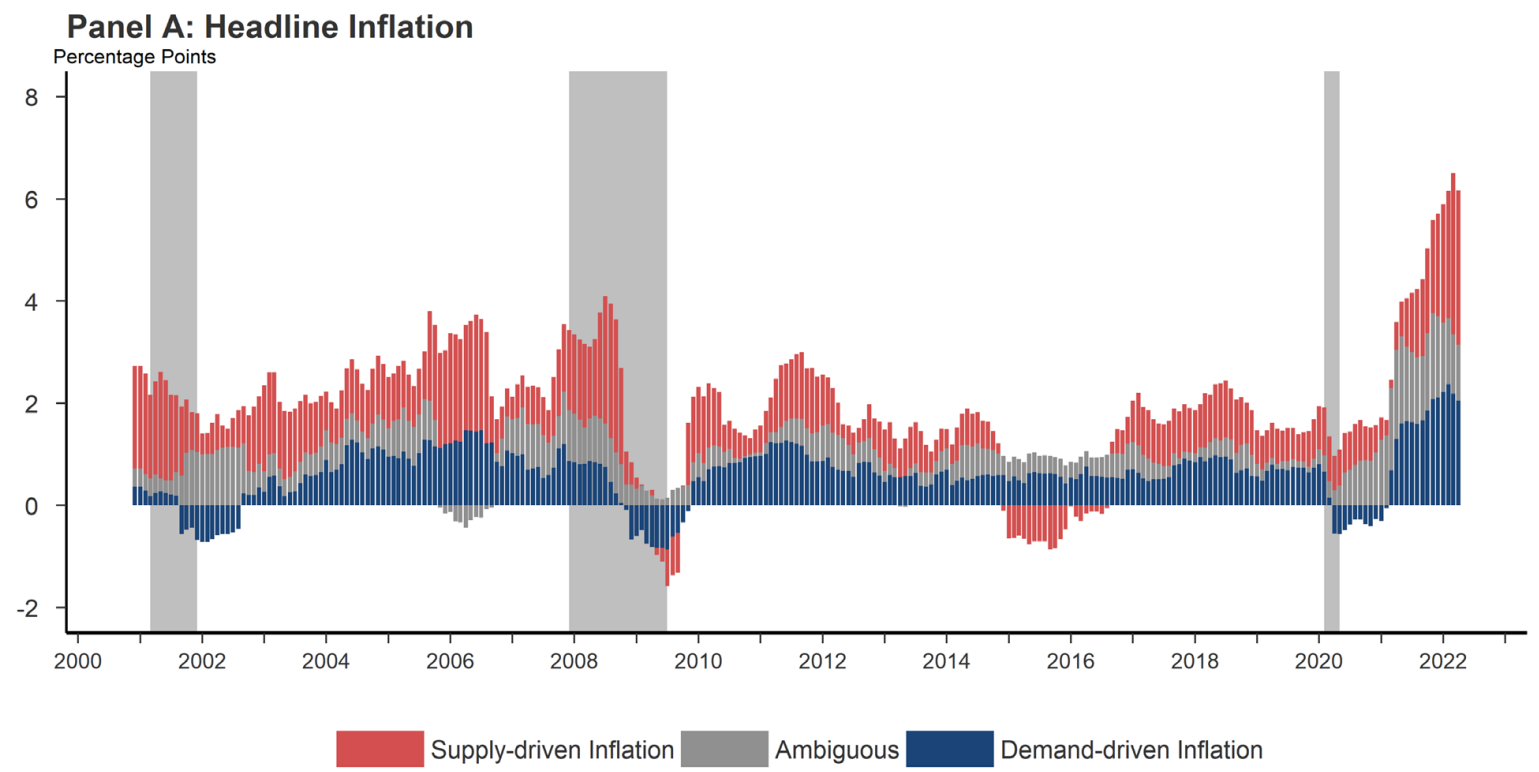

Panel B: Core Inflation

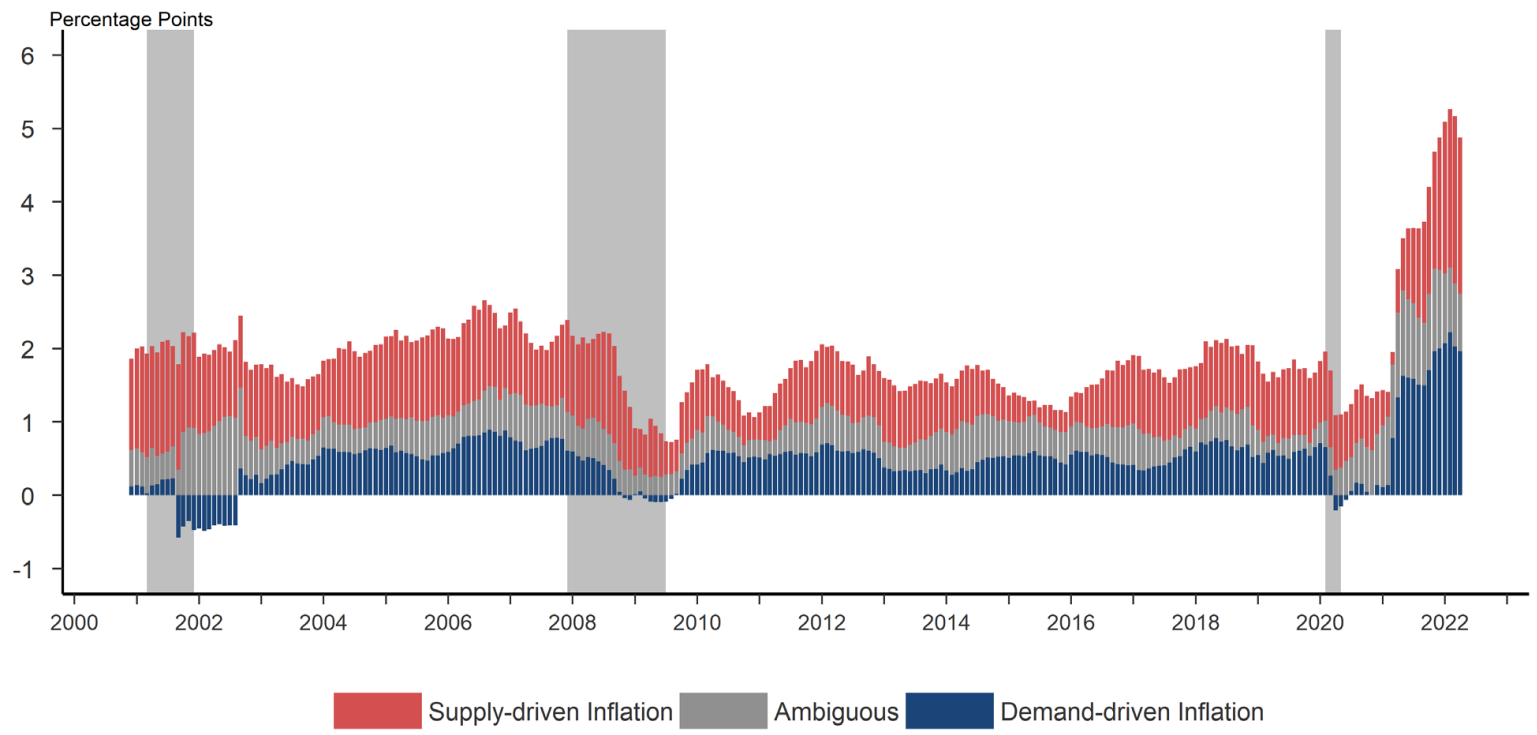

Notes: The top panel shows the contributions supply- and demand-driven headline PCE inflation. Supplydriven categories are those with a surprise price and quantity change of the opposite sign in a given month. Demand-driven categories are those with a surprise price and quantity change of the same sign in a given month. Ambiguous categories are those with either a surprise price or quantity change that was sufficiently close to zero. The bottom panel shows the same decôthposition for core PCE inflation. 
Table 2: Categories by Sensitivity to Covid-19

\begin{tabular}{|c|c|c|c|c|c|c|c|c|}
\hline Category & Insen & Dem & Sup & $\mathrm{Amb}$ & $\beta_{i}^{\pi, 1}$ & $\mathrm{SE}$ & $\beta_{i}^{x, 1}$ & $\mathrm{SE}$ \\
\hline Major Household Appliances & 0 & 0 & 1 & 0 & 0.032 & 0.013 & -0.15 & 0.016 \\
\hline Window Coverings & 0 & 0 & 0 & 1 & 0.028 & 0.019 & -0.10 & 0.021 \\
\hline Photographic Equip & 0 & 0 & 0 & 1 & 0.027 & 0.017 & -0.14 & 0.020 \\
\hline Social Advocacy/Civic/Social Organizations & 0 & 0 & 1 & 0 & 0.024 & 0.0018 & -0.35 & 0.065 \\
\hline Household Paper Products & 0 & 1 & 0 & 0 & 0.023 & 0.0067 & 0.082 & 0.0082 \\
\hline Flowers, Seeds \& Potted Plants & 0 & 0 & 1 & 0 & 0.023 & 0.0087 & -0.100 & 0.025 \\
\hline Musical Instruments & 0 & 0 & 1 & 0 & 0.021 & 0.0089 & -0.24 & 0.030 \\
\hline Video \& Audio Equip & 0 & 0 & 0 & 1 & 0.017 & 0.0079 & -0.079 & 0.014 \\
\hline Clock/Lamp/Lighting Fixture & 0 & 0 & 0 & 1 & 0.016 & 0.014 & -0.19 & 0.017 \\
\hline Misc Household Products & 0 & 0 & 0 & 1 & 0.013 & 0.0063 & 0.065 & 0.015 \\
\hline Household Cleaning Products & 0 & 0 & 0 & 1 & 0.012 & 0.0058 & 0.085 & 0.0076 \\
\hline Tools, Hardware \& Supplies & 1 & 0 & 0 & 0 & 0.011 & 0.0065 & -0.023 & 0.017 \\
\hline Household Care Services & 0 & 0 & 1 & 0 & 0.011 & 0.0029 & -0.61 & 0.016 \\
\hline Social Assistance & 0 & 0 & 1 & 0 & 0.0083 & 0.0019 & -0.049 & 0.012 \\
\hline Motor Vehicle Maintenance \& Repair & 0 & 0 & 1 & 0 & 0.0069 & 0.0025 & -0.19 & 0.015 \\
\hline Photo Processing & 0 & 0 & 0 & 1 & 0.0067 & 0.012 & -0.48 & 0.027 \\
\hline Watches & 0 & 0 & 0 & 1 & 0.0057 & 0.024 & -0.38 & 0.028 \\
\hline Package Tours & 0 & 0 & 0 & 1 & 0.0052 & 0.0049 & -0.81 & 0.028 \\
\hline Amusement Parks/Campgrounds & 0 & 0 & 0 & 1 & 0.0050 & 0.0049 & -0.58 & 0.023 \\
\hline Tobacco & 1 & 0 & 0 & 0 & 0.0046 & 0.0053 & 0.0042 & 0.015 \\
\hline Cosmetic/Perfumes/Bath/Nail Preparations & 0 & 0 & 0 & 1 & 0.0045 & 0.0063 & -0.12 & 0.011 \\
\hline Membership Clubs/Participant Sports Centers & 0 & 0 & 0 & 1 & 0.0045 & 0.0089 & -0.50 & 0.024 \\
\hline Stationery \& Misc Printed Mtls & 0 & 0 & 0 & 1 & 0.0042 & 0.0097 & -0.038 & 0.014 \\
\hline Clothing \& Footwear Services & 0 & 0 & 0 & 1 & 0.0038 & 0.0021 & -0.30 & 0.011 \\
\hline Nursing Homes & 0 & 0 & 0 & 1 & 0.0037 & 0.0041 & -0.036 & 0.0089 \\
\hline Admis to Specified Spect Amusements & 0 & 0 & 0 & 1 & 0.0036 & 0.0087 & -0.77 & 0.035 \\
\hline Video Media Rental & 1 & 0 & 0 & 0 & 0.0034 & 0.0091 & 0.0035 & 0.024 \\
\hline Telecommunication Services & 1 & 0 & 0 & 0 & 0.0033 & 0.0089 & -0.024 & 0.012 \\
\hline Elec Appliances for Personal Care & 1 & 0 & 0 & 0 & 0.0033 & 0.0064 & -0.019 & 0.011 \\
\hline Hair/Dental/Shave & 1 & 0 & 0 & 0 & 0.0033 & 0.0064 & 0.011 & 0.0084 \\
\hline Outdoor Equip \& Supplies & 1 & 0 & 0 & 0 & 0.0028 & 0.0060 & 0.012 & 0.016 \\
\hline Educational Books & 0 & 0 & 0 & 1 & 0.0025 & 0.0079 & -0.073 & 0.019 \\
\hline Commercial \& Vocational Schools & 0 & 0 & 0 & 1 & 0.0021 & 0.0041 & -0.13 & 0.017 \\
\hline Museums \& Libraries & 0 & 0 & 0 & 1 & 0.0020 & 0.0070 & -0.56 & 0.021 \\
\hline Telephone and Related Comm Equip & 0 & 0 & 0 & 1 & 0.0019 & 0.015 & -0.26 & 0.023 \\
\hline
\end{tabular}


Table 2: Categories by Sensitivity to Covid-19

\begin{tabular}{|c|c|c|c|c|c|c|c|c|}
\hline Category & Insen & Dem & Sup & Amb & $\beta_{i}^{\pi, 1}$ & $\mathrm{SE}$ & $\beta_{i}^{x, 1}$ & $\mathrm{SE}$ \\
\hline Hospitals & 0 & 0 & 0 & 1 & 0.0019 & 0.0022 & -0.33 & 0.0079 \\
\hline Expenditures Abroad by U.S. Residents & 1 & 0 & 0 & 0 & 0.0016 & 0.021 & -0.021 & 0.039 \\
\hline Dental Services & 0 & 0 & 0 & 1 & 0.0016 & 0.0029 & -0.48 & 0.0091 \\
\hline Labor Organization Dues & 0 & 0 & 0 & 1 & 0.0014 & 0.0020 & -0.28 & 0.0044 \\
\hline Nursery, Elementary \& Secondary Schools & 0 & 0 & 0 & 1 & 0.0013 & 0.0014 & -0.13 & 0.0074 \\
\hline Rental of Tenant-Occupied Nonfarm Housing & 1 & 0 & 0 & 0 & 0.00091 & 0.0015 & -0.0032 & 0.0059 \\
\hline Child Care & 0 & 0 & 0 & 1 & 0.00080 & 0.0022 & -0.34 & 0.019 \\
\hline Domestic Services & 0 & 0 & 0 & 1 & 0.00073 & 0.0040 & -0.14 & 0.012 \\
\hline Net Household Insurance & 1 & 0 & 0 & 0 & 0.00070 & 0.0034 & -0.0032 & 0.0079 \\
\hline Photo Studios & 0 & 0 & 0 & 1 & 0.00048 & 0.0094 & -0.75 & 0.0074 \\
\hline Group Housing & 1 & 0 & 0 & 0 & 0.00042 & 0.0015 & -0.00067 & 0.012 \\
\hline Imputed Rent Owner-Occupied NF Hous & 1 & 0 & 0 & 0 & 0.00037 & 0.0015 & 0.00047 & 0.00065 \\
\hline Food Furn to Empls Price Idx & 0 & 0 & 0 & 1 & 0.00026 & 0.012 & -0.17 & 0.0052 \\
\hline Purchased Meals \& Beverages & 0 & 0 & 0 & 1 & 0.00018 & 0.0013 & -0.37 & 0.0069 \\
\hline Garbage \& Trash Collection & 1 & 0 & 0 & 0 & 0.00013 & 0.0047 & -0.0015 & 0.014 \\
\hline Rental Value of Farm Dwellings & 1 & 0 & 0 & 0 & 0.000028 & 0.011 & -0.000089 & 0.0017 \\
\hline Other Household Services & 0 & 0 & 0 & 1 & -0.00037 & 0.0052 & -0.093 & 0.0041 \\
\hline Paramedical Services & 0 & 0 & 0 & 1 & -0.00045 & 0.0019 & -0.19 & 0.0049 \\
\hline Repr of Audio-Visual/Photo & 0 & 0 & 0 & 1 & -0.00051 & 0.0038 & -0.43 & 0.031 \\
\hline Physician Services & 0 & 0 & 0 & 1 & -0.00065 & 0.0026 & -0.28 & 0.0091 \\
\hline Small Elec Household Appliances & 1 & 0 & 0 & 0 & -0.00100 & 0.0095 & -0.014 & 0.012 \\
\hline Housing at Schools & 0 & 0 & 0 & 1 & -0.0011 & 0.0014 & -0.53 & 0.0025 \\
\hline Corrective Eyeglasses \& Contact Lenses & 0 & 0 & 0 & 1 & -0.0012 & 0.0049 & -0.29 & 0.014 \\
\hline Info Processing Equip & 1 & 0 & 0 & 0 & -0.0012 & 0.0091 & -0.021 & 0.016 \\
\hline Higher Education & 0 & 0 & 0 & 1 & -0.0015 & 0.0027 & -0.031 & 0.0029 \\
\hline Net Health Insurance & 1 & 0 & 0 & 0 & -0.0017 & 0.0044 & -0.00075 & 0.011 \\
\hline Water Supply \& Sewage Maintenance & 1 & 0 & 0 & 0 & -0.0019 & 0.0028 & 0.0023 & 0.0028 \\
\hline Life Insurance & 1 & 0 & 0 & 0 & -0.0021 & 0.0030 & 0.0092 & 0.023 \\
\hline Motorcycles & 0 & 0 & 0 & 1 & -0.0022 & 0.028 & -0.14 & 0.048 \\
\hline Dishes and Flatware & 0 & 0 & 0 & 1 & -0.0030 & 0.028 & -0.16 & 0.026 \\
\hline Veterinary \& Other Services for Pets & 0 & 0 & 0 & 1 & -0.0032 & 0.0027 & -0.28 & 0.0082 \\
\hline Legal Services & 0 & 0 & 0 & 1 & -0.0034 & 0.0064 & -0.087 & 0.026 \\
\hline Prof Assn Dues & 0 & 0 & 0 & 1 & -0.0034 & 0.0064 & -0.40 & 0.066 \\
\hline Nonprofit Institutions & 0 & 0 & 0 & 1 & -0.0037 & 0.0050 & 0.57 & 0.018 \\
\hline Carpets \& Other Floor Coverings & 0 & 0 & 0 & 1 & -0.0040 & 0.010 & -0.11 & 0.020 \\
\hline Standard Clothing Issued to Military Pers & 1 & 0 & 0 & 0 & -0.0041 & 0.0032 & 0.0027 & 0.023 \\
\hline
\end{tabular}


Table 2: Categories by Sensitivity to Covid-19

\begin{tabular}{|c|c|c|c|c|c|c|c|c|}
\hline Category & Insen & Dem & Sup & Amb & $\beta_{i}^{\pi, 1}$ & $\mathrm{SE}$ & $\beta_{i}^{x, 1}$ & $\mathrm{SE}$ \\
\hline Tires & 0 & 0 & 0 & 1 & -0.0041 & 0.0070 & -0.13 & 0.016 \\
\hline Cable, Satellite \& Oth Live Television Svc & 1 & 0 & 0 & 0 & -0.0041 & 0.0043 & -0.014 & 0.012 \\
\hline Recreational Books & 0 & 0 & 0 & 1 & -0.0043 & 0.011 & -0.061 & 0.022 \\
\hline Funeral \& Burial Services & 0 & 0 & 0 & 1 & -0.0044 & 0.0021 & -0.26 & 0.036 \\
\hline Luggage \& Similar Personal Items & 0 & 0 & 0 & 1 & -0.0046 & 0.011 & -0.43 & 0.015 \\
\hline New Autos & 0 & 0 & 0 & 1 & -0.0046 & 0.0043 & -0.35 & 0.043 \\
\hline Sporting Equip, Supplies, Guns \& Ammo & 0 & 0 & 0 & 1 & -0.0046 & 0.0062 & -0.038 & 0.016 \\
\hline Games, Toys \& Hobbies & 1 & 0 & 0 & 0 & -0.0050 & 0.0068 & 0.020 & 0.016 \\
\hline Accting \& Other Business Services & 0 & 0 & 0 & 1 & -0.0052 & 0.010 & -0.26 & 0.0050 \\
\hline Accessories \& Parts & 0 & 0 & 0 & 1 & -0.0054 & 0.0045 & -0.17 & 0.012 \\
\hline Moving, Storage \& Freight Services & 0 & 0 & 0 & 1 & -0.0058 & 0.016 & -0.13 & 0.018 \\
\hline Repair of HH Appliances & 1 & 0 & 0 & 0 & -0.0061 & 0.011 & -0.073 & 0.036 \\
\hline Repair of Furn, Furnishings & 1 & 0 & 0 & 0 & -0.0061 & 0.011 & -0.083 & 0.046 \\
\hline Pharmaceutical Products & 1 & 0 & 0 & 0 & -0.0062 & 0.0053 & 0.019 & 0.0086 \\
\hline New Light Trucks & 0 & 0 & 0 & 1 & -0.0062 & 0.0029 & -0.26 & 0.039 \\
\hline Net Motor Vehicle/Oth Trans Insur & 0 & 0 & 0 & 1 & -0.0065 & 0.0049 & -0.094 & 0.0066 \\
\hline Therapeutic Medical Equip & 0 & 0 & 0 & 1 & -0.0072 & 0.0082 & -0.14 & 0.012 \\
\hline Other Medical Products & 0 & 0 & 0 & 1 & -0.0072 & 0.0082 & -0.14 & 0.012 \\
\hline Postal \& Delivery Services & 0 & 0 & 0 & 1 & -0.0077 & 0.0063 & 0.13 & 0.012 \\
\hline Household Linens & 0 & 0 & 0 & 1 & -0.0096 & 0.020 & -0.14 & 0.021 \\
\hline Newspapers \& Periodicals & 0 & 0 & 0 & 1 & -0.0100 & 0.010 & 0.11 & 0.018 \\
\hline Pets \& Related Products & 0 & 0 & 0 & 1 & -0.011 & 0.0046 & 0.027 & 0.0094 \\
\hline Sales Receipts Foundatns/Grant Making & 0 & 1 & 0 & 0 & -0.011 & 0.0032 & -0.29 & 0.072 \\
\hline Lotteries & 0 & 1 & 0 & 0 & -0.011 & 0.0029 & -0.14 & 0.0032 \\
\hline Casino Gambling & 0 & 1 & 0 & 0 & -0.011 & 0.0029 & -0.72 & 0.019 \\
\hline Pari-Mutuel Net Receipts & 0 & 1 & 0 & 0 & -0.011 & 0.0029 & -0.48 & 0.040 \\
\hline Financial Svc Charges, Fees/Comm & 1 & 0 & 0 & 0 & -0.011 & 0.011 & 0.028 & 0.014 \\
\hline Furniture & 0 & 1 & 0 & 0 & -0.015 & 0.0064 & -0.18 & 0.015 \\
\hline Ground Transportation & 0 & 1 & 0 & 0 & -0.019 & 0.0058 & -0.65 & 0.013 \\
\hline Less Pers Remit in Kind to Nonres & 0 & 0 & 0 & 1 & -0.020 & 0.0072 & -0.027 & 0.12 \\
\hline Religious Organizations' Services to HHs & 0 & 1 & 0 & 0 & -0.023 & 0.0036 & -0.019 & 0.0038 \\
\hline Men's \& Boys' Clothing & 0 & 1 & 0 & 0 & -0.024 & 0.0084 & -0.37 & 0.011 \\
\hline Financial Services Furnished w/out Payment & 0 & 0 & 0 & 1 & -0.024 & 0.0095 & -0.016 & 0.010 \\
\hline Other Motor Vehicle Services & 0 & 1 & 0 & 0 & -0.024 & 0.0070 & -0.26 & 0.0093 \\
\hline Maint/Repair of Rec Vehicles/Sports Eqpt & 0 & 1 & 0 & 0 & -0.026 & 0.0071 & -0.57 & 0.0041 \\
\hline Nonelectric Cookware \& Tableware & 0 & 1 & 0 & 0 & -0.026 & 0.011 & -0.14 & 0.015 \\
\hline
\end{tabular}


Table 2: Categories by Sensitivity to Covid-19

\begin{tabular}{lcccccccc} 
Category & Insen & Dem & Sup & Amb & $\beta_{i}^{\pi, 1}$ & SE & $\beta_{i}^{x, 1}$ & SE \\
\hline Used Light Trucks & 0 & 1 & 0 & 0 & -0.030 & 0.0075 & -0.27 & 0.032 \\
Pleasure Boats, Aircraft & 0 & 1 & 0 & 0 & -0.032 & 0.012 & -0.24 & 0.032 \\
Internet Access & 0 & 0 & 0 & 1 & -0.032 & 0.0063 & 0.023 & 0.011 \\
Bicycles \& Acc & 0 & 0 & 0 & 1 & -0.033 & 0.012 & -0.010 & 0.021 \\
Less Exps in the US by Nonres & 0 & 1 & 0 & 0 & -0.034 & 0.0055 & -0.47 & 0.024 \\
Jewelry & 0 & 0 & 0 & 1 & -0.035 & 0.017 & -0.36 & 0.024 \\
Film \& Photographic Supplies & 0 & 0 & 0 & 1 & -0.036 & 0.030 & -0.078 & 0.031 \\
Water Transportation & 0 & 1 & 0 & 0 & -0.044 & 0.0098 & -0.58 & 0.039 \\
Shoes \& Other Footwear & 0 & 1 & 0 & 0 & -0.048 & 0.0076 & -0.39 & 0.014 \\
Women's \& Girls' Clothing & 0 & 1 & 0 & 0 & -0.049 & 0.010 & -0.38 & 0.014 \\
Foreign Travel by U.S. Residents & 0 & 1 & 0 & 0 & -0.060 & 0.0075 & -0.67 & 0.022 \\
Used Autos & 0 & 1 & 0 & 0 & -0.065 & 0.0085 & -0.25 & 0.033 \\
Children's \& Infants' Clothing & 0 & 1 & 0 & 0 & -0.066 & 0.014 & -0.22 & 0.017 \\
Clothing Materials & 0 & 1 & 0 & 0 & -0.066 & 0.020 & -0.10 & 0.031 \\
Sewing Items & 0 & 1 & 0 & 0 & -0.066 & 0.020 & -0.12 & 0.028 \\
Hotels and Motels & 0 & 1 & 0 & 0 & -0.11 & 0.013 & -0.64 & 0.015 \\
Air Transportation & 0 & 1 & 0 & 0 & -0.16 & 0.020 & -0.72 & 0.020 \\
\hline
\end{tabular}

